\title{
Psychometric Evidence of the 10-Item Connor-Davidson Resilience Scale (CD-RISC10, Greek Version) and the Predictive Power of Resilience on Well-Being and Distress
}

\author{
Theodoros Kyriazos* ${ }^{*}$, Anastasios Stalikas \\ Department of Psychology, Panteion University, Athens, Greece \\ Email: *th.kyriazos@gmail.com
}

How to cite this paper: Kyriazos, T., \& Stalikas, A. (2021). Psychometric Evidence of the 10-Item Connor-Davidson Resilience Scale (CD-RISC10, Greek Version) and the Predictive Power of Resilience on Well-Being and Distress. Open Journal of Social Sciences, 9, 280-308.

https://doi.org/10.4236/jss.2021.911022

Received: September 30, 2021

Accepted: November 27, 2021

Published: November 30, 2021

Copyright () 2021 by author(s) and Scientific Research Publishing Inc. This work is licensed under the Creative Commons Attribution International License (CC BY 4.0).

http://creativecommons.org/licenses/by/4.0/

(c) (i) Open Access

\begin{abstract}
The purpose of this study was to evaluate the construct validity of CD-RISC10 in a sample of 1089 Greek adults of the general population. The CD-RISC10 factor structure was evaluated first with EFA in a $20 \%$ subsample and confirmed with CFA (CFA1) in a different $40 \%$ subsample. A cross-validation CFA followed (CFA2) in a third $40 \%$ subsample (i.e. of equal power with CFA1). Model fit comparison using $-2 \Delta L L$ difference test suggested a bidimensional structure but bifactor ancillary measures indicated that multidimensionality was weak to exclude the unidimensional structure. Full weak measurement invariance across gender for this unidimensional model was successfully established in the entire sample. Partial strong measurement invariance was established after freeing intercepts of 2 items and partial strict after freeing the error variance of 1 item. Internal consistency reliability ( $\alpha$ ) was equal to three different model-based reliability calculations (CR) at adequate levels (.85), corroborating one another, although CD-RISC10 was not tau-equivalent. The average variance extracted was .37 to evaluate model-based convergent validity. Convergent and discriminant validity were evaluated further with correlation analysis with a resilience measure, life satisfaction, affectivity, depression, anxiety, and stress with all associations to the expected direction. The predictive validity of CD-RISC10 was evaluated with a SEM model of resilience regressed on two higher-order latent factors of subjective well-being (SWB) and psychological distress, yielding significant strong positive and negative effects respectively. Male scored significantly higher than females thus, normative data were calculated over the total sample and also separately by gender.
\end{abstract}




\section{Keywords}

Resilience, CD-RISC10, Factor Analysis, Validation, Bifactor, CFA, EFA, SEM, Normative Data

\section{Introduction}

Strangely, about a third of the animals and people who experience inescapable shocks or noise resist helplessness. Why they are so resilient? (Seligman, 2011). Resilience is a dynamic, multifaced process of positive adaptation when facing adversity, stress or trauma (Campbell-Sills \& Stein, 2007). Resilience reliably mirrors how capable one is to handle stress (Aloba et al., 2016). It is one of the treatment outcomes in anxiety, depression, and stress responses (Connor \& Davidson, 2003), encompassing attitudes and behaviours that foster adaptive coping strategies during stressful circumstances (Burns \& Anstey, 2010).

When dealing with adversity, resilient individuals use internal personal resources-genetic, biological, psychological-as well as external-interpersonal and environmental (Campbell-Sills \& Stein, 2007; Cheng, Dong, He, Zhong, \& Yao, 2020; Connor \& Davidson, 2003). A meta-analysis (Hu, Zhang, \& Wang, 2015) showed that resilience contributed to sustaining mental health and preventing mental distress. Resilient individuals cope with stressors, a process associated with psychological well-being, life satisfaction, positive emotions, and negatively associated with emotional and behavioral problems (Kavčič, Kocjan, \& Dolenc, 2021).

Windle, Bennett, \& Noyes (2011) and Salisu \& Hashim (2017) reviewed resilience measures, ranking CD-RISC10 (Campbell-Sills \& Stein, 2007), among the most popular with good psychometric qualities.

\subsection{Connor-Davidson Resilience Scale, 10-Item Version (CD-RISC10)}

The stability of the CD-RISC25 structure (Connor \& Davidson, 2003) was questionable due to varying items (21 - 22) and/or factors (1 - 6), see Nartova-Bochaver, Korneev and Bochaver (2021). Other questionable issues during the CD-RISC25 development involved: 1) inconsistent loadings across Exploratory Factor Analyses (EFAs); 2) an item with no salient loading and 3) factors containing too few items or disparate theoretical underpinning (Campbell-Sills \& Stein, 2007). These controversies led to shorter CD-RISC versions with 10 items (Campbell-Sills \& Stein, 2007) or 2 items (Vaishnavi, Connor, \& Davidson, 2007; out of the scope of this study).

Campbell-Sills and Stein (2007) proposed a unidimensional version of the CD-RISC, keeping 10 items measuring tolerance of negative experiences, pressure, change, personal problems, and painful feelings, reflecting a cognitive dimension of resilience (Madewell \& Ponce-Garcia, 2016). 
For the CD-RISC10 development, Campbell-Sills and Stein (2007) used three undergraduate samples, including a subsample of 131 individuals who self-reported childhood trauma and psychiatric symptoms to evaluate construct validity. In the first two samples Exploratory Factor Analysis (EFA) was carried out, and in the third Confirmatory Factor Analysis (CFA). The EFAs showed an unstable factor structure. Based on CFA, empirically-driven exclusion of items followed, proposing a unidimensional scale, preferred over a two-dimensional alternative with hardiness and persistence factors. The unidimensional CD-RISC10 had good internal consistency (.85) and construct validity verifying that resilience moderated the impact of childhood maltreatment on current psychiatric symptoms.

Currently, there are more than 80 translations of the CD-RISC (Nartova-Bochaver et al., 2021), including Malayalam (Aswini \& Deb, 2019), Peruvian (Levey et al., 2021) and Russian (Nartova-Bochaver et al., 2021) and numerous validations of the scale both in the general population and special samples.

Furthermore, in consistency with the resilience literature (see Singh et al., 2016) a meta-analysis reported that gender significant moderates the association of resilience with mental health (Hu et al., 2015). Campbell-Sills, Forde and Stein (2009) also found that females of the general population scored significantly lower than males on the CD-RISC10. This finding was replicated, e.g. with medical students from Canada (Rahimi, Baetz, Bowen, \& Balbuena, 2014), elderly (Meng et al., 2019), undergraduates, and depressive patients from China (Cheng et al., 2020), youngsters from Russia (Nartova-Bochaver et al., 2021), or public accountants from the US (Smith et al., 2018).

\subsection{CD-RISC10 Validation Studies}

Regarding the factor structure, validation studies on the general population confirmed the unidimensional structure for the versions from Australia (Burns \& Anstey, 2010), Germany (Wollny \& Jacobs, 2021), Russia (Nartova-Bochaver et al., 2021), Slovenia (Kavčič et al., 2021), China (Cheng et al., 2020) and Spain (Notario-Pacheco et al., 2011). Equally, a large body of literature on special populations also supported the unidimensional structure, i.e. US distance runners (Gonzalez et al., 2016), US college students with stress or trauma (Madewell \& Ponce-Garcia, 2016), Chinese parents of children with cancer (Ye et al., 2017), Chinese elderly (Meng et al., 2019), or Chinese undergraduates and depressive patients (Cheng et al., 2020), and Spanish non-professional caregivers (Blanco et al., 2019). Conversely, a few validation studies on special populations proposed a bidimensional structure, i.e. nursing students from Nigeria (Aloba et al., 2016), or accounting/business students from the US (Smith et al., 2019), the later proposing a second order bidimensional structure. Lastly, a study on elderly from Finland suggested that CD-RISC was unidimensional for ages $<75$ years and bidimensional for ages $\geq 75$ (Tourunen et al., 2021).

The internal consistency reliability of the CD-RISC10 was adequate across 
studies. Specifically, for the studies in the general population Cronbach's alpha was .81 in the German sample (Wollny \& Jacobs, 2021), .84 in the Russian sample (Nartova-Bochaver et al., 2021), .85 in the Spanish sample (Notario-Pacheco et al., 2011) and > .76 in the Slovenian sample (Kavčič et al., 2021).

Furthermore, several studies tested full and partial measurement invariance of the CD-RISC10 across gender. For example, measurement invariance was evaluated in Australian distance runners (Gonzalez et al., 2016), or Australian community sample (Burns \& Anstey, 2010), US public accountants (Smith et al., 2018), or US business and accounting students (Smith et al., 2019), Chinese undergraduates and depressive patients (Cheng et al., 2020), Chinese older adults (Meng et al., 2019), Colombian vulnerable adolescents (Guarnizo Guzmán et al., 2019), and a Slovenian community sample (Kavčič et al., 2021).

\subsection{The Present Study}

Note that the CD-RISC10 validation studies in the general population are relatively fewer than those in special populations. Therefore, useful additions to the CD-RISC10 validation literature would be validation in the general population considering the following: 1 ) given the structural instability whether CD-RISC10 is unidimensional or bidimensional, after evaluating all alternative models proposed in the literature (i.e. unidimensional, bidimensional, bidimensional higher-order), and some untested alternatives (bidimensional bifactor) to gain insights on the scale dimensionality versus multidimensionality (c.f. Hammer \& Toland, 2016); 2) given the gender differences in scoring, and the limited measurement invariance studies for the general population; whether CD-RISC10 items measure resilience invariantly across gender and 3) given the potential gender differences to provide normative data both for the general Greek population and for each gender separately.

Therefore, extending the CD-RISC10 validation studies for the general population with this validation in the Greek context adopted a cross-sectional design with the following objectives: (a) to evidence the construct validity of the CD-RISC10, using a multistage validation process testing alternative models (Kyriazos, 2018a); (b) to test the measurement invariance across gender; (c) to test the internal consistency reliability and the model-based reliability; (d) to test the convergent and discriminant validity; (e) to test the predictive validity of resilience on psychological distress and subjective well-being; (f) to provide professionals with normative data for the general Greek population, and for each gender.

\section{Methods}

\subsection{Participants and Procedure}

Inclusion criteria were age $\geq 18$ years, and absence of mental illness or insufficient cognitive ability. The sample involved 1089 Greek adults (65\% females). About one in five (19\%) were from 18 - 20 years, $29 \%$ from 21 - 30 years, $16 \%$ 
from 31 - 40, 20\% from 41 - 50 years, 14\% from 51 - 60 years and 2.5\% were $>60$ years. More than one in two respondents were never married (55\%), married (38\%) or other (7\%). Most were employees (50\%), self-employed (17\%), university students (16\%), unemployed (8\%), other $(10 \%)$ with either a tertiary level education or higher $(78 \%)$, or a secondary level education or lower $(22 \%)$.

The questionnaire was administered online, after obtaining informed consent. Data were collected with the network sampling method. Psychology students (2018-2019) voluntarily recruited participants of their social environment, receiving extra course credit. Recruitment rules permitted students to recruit at least 10 non-student participants each, without taking the questionnaire themselves.

\subsection{Sample Power Analysis}

A priori power analysis based on the RMSEA (MacCallum, Browne, \& Sugawara, 1996) for the unidimensional CD-RISC10 model (Campbell-Sills \& Stein, 2007) suggested that a sample of $N=279$ was required for achieving a power of approximately $80 \%$ to reject a wrong model $(d f=35$, RMSEA $=.05$, alpha $=.05)$. See Results for post hoc power analysis.

\subsection{Measures}

\subsubsection{Connor-Davidson Resilience Scale, 10 -Item Version (CD-RISC10)}

CD-RISC10 (Campbell-Sills \& Stein, 2007) is a short version of the original CD-RISC (Connor \& Davidson, 2003). It is a self-report, measure of resilience with 10 items (e.g. "Coping with stress can strengthen me") rated on a 5-point scale $(0=$ Not True at All; $4=$ True Nearly All of The Time). The possible score ranges from 0 (minimum resilience) to 40 (maximum resilience).

\subsubsection{Brief Resilience Scale (BRS)}

BRS (Smith, Dalen, Wiggins, Tooley, Christopher, \& Bernard, 2008) is a brief resilience measure with 6 items (e.g., "I usually come through difficult times with little trouble") rated on a 5-point Likert scale from 1 (Strongly Disagree) to 5 (Strongly Agree). Smith et al. (2008) reported internal consistency reliability of a $=.80-.91$, and in a Greek sample (Kyriazos, Stalikas, Prassa, Galanakis, Yotsidi, \& Lakioti, 2018) it was $\alpha=.80$. In this study, internal consistency reliability was $\alpha=.73$.

\subsubsection{Scale of Positive and Negative Experience 8 (SPANE-8)}

SPANE-8 (Diener et al., 2010; Kyriazos, Stalikas, Prassa, \& Yotsidi, 2018a) is a shorter version of SPANE-12, containing 1 general experience per factor instead of originally 3 (Diener et al., 2010: p. 145). Items are rated on a 5-point Likert scale $(1=$ Very Rarely or Never to $5=$ Very Often or Always). Internal consistency reliability for SPANE-P and SPANE-N were .90 and .85 respectively in a Greek sample (see Kyriazos et al., 2018a). In this study, it was $\alpha=.86$ (SPANE-P) and .79 (SPANE-N). 


\subsubsection{Depression Anxiety Stress Scale, 9 Item Version (DASS-9)}

This is a shorter version of DASS-21 (Lovibond \& Lovibond, 1995; Yusoff, 2013; Kyriazos, Stalikas, Prassa, \& Yotsidi, 2018b) with 3 items per factor instead of 7 in the original. Kyriazos et al. (2018b) reported internal consistency reliability of $\alpha=.79$ (Depression), .77 (Anxiety), and .73 (Stress) in a Greek sample. In this study, internal consistency reliability was $\alpha=.70$ (Depression), .78 (Anxiety), and .62 (Stress).

\subsubsection{Satisfaction with Life Scale (SWLS)}

The SWLS (Diener, Emmons, Larsen, \& Griffin, 1985) measures perceived global life satisfaction (e.g. "I am satisfied with my life") on a 7-point scale, from 1 (Strongly Disagree) to 7 (Strongly Agree), midpoint $=$ Neither Agree nor Disagree. Diener et al. (1985) reported that Cronbach's alpha was .87 and in a Greek sample it was .87 (Kyriazos, Galanakis, Karakasidou, \& Stalikas, 2021a). In this study, Cronbach's alpha was .88.

\subsubsection{Data Diagnostics and Analytic Strategy}

Note that in all instances MLR estimator was used to estimate the CFA and SEM models, treating data as continuous. CD-RISC10 is rated on a five-point scale, which is a "grey zone", heavily debated whether it is continuous (Li, 2016; Raykov, 2012; Rigdon, 1998) or ordinal (Kline, 2016). However, in practice, empirical researchers suggested using MLR in CFA models when the number of response categories was $\geq 5$ ( $\mathrm{Li}, 2016$ ). Data was also treated as continuous because treating variables in the CFAs and SEM as ordinal would mean that every other analysis on the same variables should also treat them as ordinal, thus affecting correlation coefficients, mean comparisons, and even reliability coefficients (see Gadermann, Guhn, \& Zumbo, 2012). It would also be unfamiliar to the reader, generating incomparable results to existing validation studies. Data were analyzed with R software (R Development Core Team, 2021).

The sample was randomly divided into three $(20 \%, 40 \%, 40 \%)$ to carry out EFA (20\%), an initial CFA1 (40\%) and cross-validating CFA2 (40\%) in three different subsamples: i.e. EFA followed by two CFAs of equal sample power, in a multistage validation process (3-faced construct validation method, Kyriazos, 2018a).

The assumption of univariate and multivariate normality was examined in the whole data set and in the three subsamples separately. Multivariate outliers were evaluated using Mahalanobis distance at $\alpha=.001$ for the critical $\chi^{2}$ value (Tabachnick \& Fidell, 2013).

Initially, EFA was performed in the $20 \%$ subsample to establish a structure. The number of factors to retain was examined with Parallel Analysis (PA; Horn, 1965), Very Simple Structure (VSS; Revelle \& Rocklin, 1979), Minimum Average Partial Correlations (MAP; Velicer, 1976) and Bayesian information criterion (BIC). The goodness of the EFA model fit was evaluated with the Root Mean Square Error of Approximation (RMSEA), Root Mean Square of Residuals (RMSR), Tucker-Lewis Index (TLI). Fit criteria adopted were RMSEA $\leq .06$ [90\% CI], TLI $\geq .95$ (Hu \& Bentler, 1999), lowest possible BIC (Mair, 2018), and 
RMSR $\leq .0448$ (Kelley's criterion; Kelley, 1935).

Then the CFA1 followed in a different $40 \%$ subsample. CFA goodness of fit was evaluated with RMSEA $(\leq .06,90 \% \mathrm{CI})$, SRMR $(\leq .08)$, CFI $(\geq .95)$, TLI ( $\geq .95)$, (Hu \& Bentler, 1999), the normed chi-square ratio $\left(\chi^{2} / \mathrm{df}\right) \leq 3$ (Carmines \& McIver, 1981), Akaike information criterion (AIC) and BIC (the lower the better; Mair, 2018). Bifactor ancillary measures were ECV $\geq .85$ suggesting a sufficiently unidimensional instrument (Stucky et al., 2014), PUC $<.80$, ECVGen $>.60$ and $\omega_{\mathrm{h}}>.70$ also suggesting not severe multidimensionality to exclude unidimensional interpretations (Reise, Bonifay, \& Haviland, 2013: p. 22). All the alternative models of CFA1 were compared with the likelihood ratio test $(-2 \Delta \mathrm{LL}$ MLR rescaled version; Satorra \& Bentler, 2010). A cross-validating CFA (CFA2) followed in a different $40 \%$ subsample to validate the optimal model of CFA1. A priori and post hoc power analysis based on the RMSEA (MacCallum et al., 1996) on the CFA2 results were calculated to estimate the power to reject a wrong model on RMSEA $=.05$, and alpha $=.05$. Then two trial CFAs were carried out (with vs without outliers) to test if outliers influenced results (Tabachnick \& Fidell, 2013).

Additional analyses were performed in this the successfully cross-validated CFA 2 model over the entire sample: 1) We examined measurement invariance of the optimal CFA2 model across gender with difference test criteria $|\Delta \mathrm{CFI}|<.010$ (Cheung \& Rensvold, 2002), $\mid \Delta$ RMSEA $\mid<.010$ (Chen, 2007). 2) Internal consistency reliability, the greatest lower bound (Jackson \& Agunwamba, 1977), model-based reliability (Mair, 2018) and model-based convergent validity (Hoque et al., 2017). Model-based reliability and convergent validity were estimated with Composite Reliability (CR; Werts, Linn, \& Karl, 1974) and Average Variance Extracted (AVE; Fornell \& Larcker, 1981) respectively. CR was calculated with the standardized factor loadings (see Raykov, 2004), using three alternative calculations, proposed by Bollen (1980), Bentler (2009) and McDonald (1999: i.e. $\omega_{t}$ ), see Kyriazos (2017) after testing tau equivalency of the optimal CFA1 model. 3) Additionally, convergent and discriminant validity were examined further with correlation analysis.

Subsequently, predictive validity was estimated by specifying a SEM model with CD-RISC10 regressed on two higher-order latent factors of Subjectivewellbeing (SWB; Diener et al., 1999) and Psychological Distress. SWB comprised the latent factors of life satisfaction (SWLS, Diener et al., 1985), and affectivity (SPANE-8 (Diener et al., 2010; Kyriazos et al., 2018a), and Psychological Distress comprised the latent factors of Depression, Anxiety, and Stress (DASS-9; Lovibond \& Lovibond, 1995; Kyriazos et al., 2018b) to examine the effects of resilience.

Finally, the scores of males and females were compared using Mann-WhitneyWilcoxon test, and assuming a significance at $p<.001$. The effect size was calculated with Vargha and Delaney (2000) interpretations (A estimate). Then normative data were calculated by converting raw scores to percentiles for the total sample and per gender separately. 
See all the steps of the Analytic Strategy in Table A1 (Appendix).

\section{Results}

\subsection{Data Diagnostics \& Sample Slitting}

There were $N=1089$ cases in the total sample. There were no missing values because all the fields of the digital survey were set as "required" (Kyriazos, $2018 b$ ). Out of the 1089 cases, there were 32 multivariate outliers, $\chi^{2}(10)=29.59$, $p<.001$ for Mahalanobis. However, outliers were not data entry errors, therefore exclusion was unsupported, final $N=1089$. The total sample $(N=1089)$ was randomly divided into three subsamples $(20 \%, 40 \%$, and $40 \%)$ to carry out the EFA, initial CFA (CFA1) and the cross-validating CFA (CFA2), see Kyriazos (2018a).

\subsection{Univariate and Multivariate Normality}

The assumption of univariate normality was examined in the whole data set $(N=$ $1089)$, and of multivariate normality in the three samples separately $\left(n_{\mathrm{EFA}}=220\right.$, $\left.n_{\mathrm{CFA} 1}=435, n_{\mathrm{CFA} 2}=434\right)$. All normality tests were significant, $p<.001$, see Table $\mathrm{A} 2$ in the Appendix.

\subsection{Exploratory Factor Analysis $\left(n_{\mathrm{EFA}}=220\right)$}

The EFA, was carried out in the EFA subsample $\left(20 \%, n_{\mathrm{EFA}}=220\right)$. Kaiser-Meyer-Olkin measure of sampling adequacy was .88, and MSA for items 1 10 ranged from $.84-.91$ (see Table 1). Bartlett's test of sphericity was significant, $\chi^{2}(10)=626.60, p<.001$. All items correlated at $\geq .22$ with at least a second item (range from .22 - .50). The largest Squared Multiple Correlation was .44 (range from $.21-.44$ ), see Table 1 . The $\mathrm{R}$ determinant was $2.045828 \mathrm{E}+34$ and the

Table 1. Factor loadings $(\lambda)$, communalities $\left(h^{2}\right)$, uniquenesses $\left(u^{2}\right)$ and item-level MSA for the 10 CD-RISC10 items from the EFA performed in the $20 \%$ subsample $\left(n_{E F A}=220\right)$.

\begin{tabular}{ccccc}
\hline Item & $\lambda$ & $h^{2}$ & $u^{2}$ & $M S A$ \\
\hline ITEM 1 & .53 & .28 & .72 & .87 \\
ITEM 2 & .69 & .47 & .53 & .86 \\
ITEM 3 & .44 & .20 & .80 & .84 \\
ITEM 4 & .40 & .16 & .84 & .84 \\
ITEM 5 & .63 & .40 & .60 & .91 \\
ITEM 6 & .67 & .45 & .55 & .88 \\
ITEM 7 & .49 & .24 & .76 & .88 \\
ITEM 8 & .65 & .42 & .58 & .90 \\
ITEM 9 & .70 & .49 & .51 & .90 \\
ITEM 10 & .66 & .43 & .57 & .89 \\
\hline
\end{tabular}

Note Extraction $=$ Principal Factor $(\mathrm{fm}=$ "pa”, No rotation. 
anti-image correlation matrix diagonals were $>.50(=1,1,1,1,1,1,1,1,1,1)$. Therefore, EFA was carried out with all ten items. A single factor was extracted, (PAF extraction). Parallel analysis suggested 1 factor (see scree plot in Figure 1) and the Velicer MAP achieved a minimum of .02 with 1 factor. VSS complexity 1 also achieved a maximum of .79 with 1 factor and BIC was minimized $(-118.75)$ with 1 factor. This single-factor structure had adequate fit, $\mathrm{RMSR}=.06$, TLI $=.922$, RMSEA $=.067$ [90\% CI .044, .091], explaining 35.4\% of the variance. The factor score was adequately correlated with its regression score at .93. Table 1 contains the factor loadings, communalities, uniquenesses, and MSA for each item.

\subsection{Confirmatory Factor Analysis (CFA1, $\left.n_{\text {CFA1 }}=435\right)$}

The CFA was performed in a different subsample $\left(40 \%, n_{\mathrm{CFAl}}=435\right)$. Four alternative CFA models were tested (Table 2). MODEL A was the original single-factor model (Campbell-Sills \& Stein, 2007), emerging from the previous EFA. MODEL B was a 2-factor model proposed by Smith et al. (2019). The first factor (Toughness) comprised items 5 - 10 and the second factor (Motivation) comprised items 1 - 3. MODEL C was a different 2-factor model proposed by Tourunen et al. (2021), with the first factor containing items 2, 5 - 10 and the second-factor items $1,3,4,7$, that is, item 7 was specified to load on both factors as proposed by Tourunen et al. (2021: p. 5). MODEL D was a Bifactor model (Harman, 1976), containing 2 specific factors (Toughness and Motivation like MODEL B), tapping simultaneously a general resilience factor. The Bifactor

\section{Parallel Analysis Scree Plots}

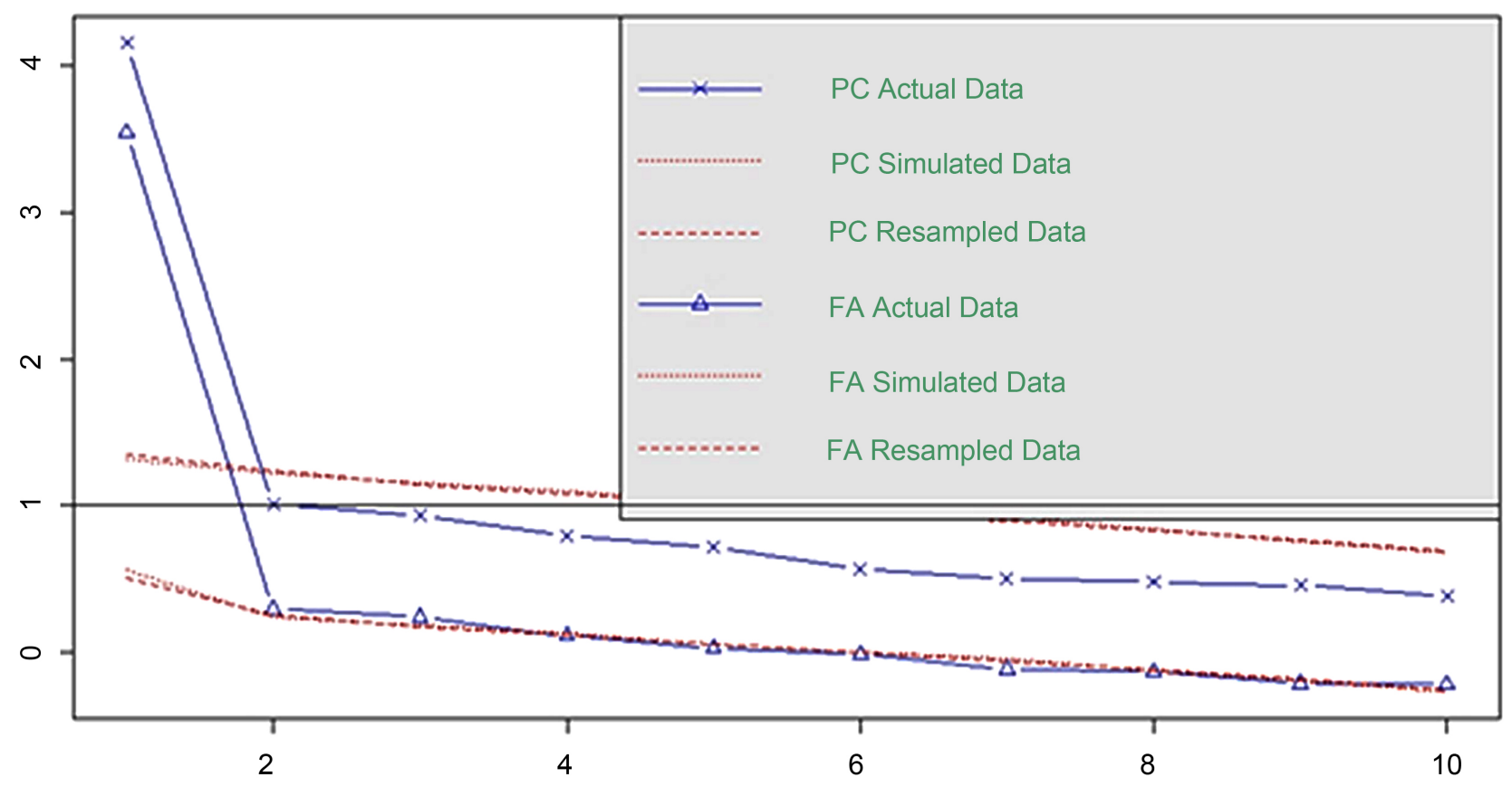

Factor/Component Number

Figure 1. Parallel analysis scree plot suggesting a single factor, based on the EFA performed in the $20 \%$ Subsample $\left(\mathrm{N}_{\mathrm{EFA}}=220\right)$. 
Table 2. Goodness of fit, factor loadings and inter-correlations for the alternative CD-RISC10 models specified in the CFA1, Carried out in the first $40 \%$ subsample $\left(\mathrm{n}_{\mathrm{CFAl}}=435\right)$.

\begin{tabular}{|c|c|c|c|c|}
\hline \multirow[b]{2}{*}{$\begin{array}{l}\text { Model fit } \\
\text { Indicator }\end{array}$} & \multicolumn{4}{|c|}{ Models Tested } \\
\hline & $\begin{array}{c}\text { MODEL A } \\
\text { 1-factor (Campbell-Sills } \\
\text { \& Stein, 2007) }\end{array}$ & $\begin{array}{c}\text { MODEL B }^{\mathrm{a}} \\
\text { 2-factor } \\
\text { (Smith et al., 2019) }\end{array}$ & $\begin{array}{c}\text { MODEL }^{\mathrm{b}} \\
\text { 2-factor (Tourunen } \\
\text { et al., 2021) }\end{array}$ & $\begin{array}{c}\text { MODEL D } \\
\text { 2-factor Bifactor }\end{array}$ \\
\hline$x^{2}$ & 82.42 & 7.25 & 75.44 & 87.42 \\
\hline$d f$ & 35 & 34 & 33 & 25 \\
\hline$\chi^{2} / d f$ & 2.35 & 2.07 & 2.29 & 3.5 \\
\hline CFI & .944 & .957 & .95 & .962 \\
\hline TLI & .928 & .943 & .932 & .931 \\
\hline RMSEA & .056 & .05 & .054 & .055 \\
\hline Low $90 \%$ CI & .043 & .035 & .041 & .038 \\
\hline High $90 \%$ CI & .069 & .064 & .068 & .072 \\
\hline SRMR & .045 & .041 & .042 & .035 \\
\hline BIC & $11,027.26$ & $11,015.6$ & $11,028.84$ & $11,044.41$ \\
\hline AIC & $10,945.76$ & $10,927.98$ & $10,939.18$ & $10,922.15$ \\
\hline Loadings per Factor & $.498-.706$ & $\begin{array}{l}\mathrm{F} 1=.497-.720 \\
\mathrm{~F} 2=.532-.715\end{array}$ & $\begin{array}{c}\mathrm{F} 1=.570-.713 \\
\mathrm{~F} 2=-.048-.592\end{array}$ & $\begin{aligned} \mathrm{F} 1 & =-.178-.459 \\
\mathrm{~F} 2 & =-.174-.568 \\
\mathrm{G} & =.478-.719\end{aligned}$ \\
\hline Factor Inter-Correlation & - & .862 & .871 & - \\
\hline
\end{tabular}

Note . Estimator = MLR; CFI = Comparative Fit Index; TLI = Tucker-Lewis index; RMSEA = Root Mean Square Error of Approximation; SRMR = Standardized Root Mean Square Residual. AIC = Akaike Information Criterion, BIC = Bayesian Information Criterion. F1 = Factor 1, F2 = Factor 2. ${ }^{a}$ Factor 1 (Toughness) $=$ items $5-10$ and Factor 2 (Motivation) $=$ items $1-3 .{ }^{b}$ Factor 1 = items 2, $5-10$ and Factor $2=$ items 1, 3, 4, 7. ' Specific Factor 1 (Toughness) = items $5-10$, Specific Factor 2 (Motivation) $=$ items $1-3, \mathrm{G}=$ general resilience factor.

Model was tested to examine if CD-RISC10 was unidimensional, multidimensional, or somewhere in-between. We could not test a 2 -factor, higher-order model (see Smith et al., 2019), because of the under-identification problems for all models with $m \leq 3$ (e.g. Wang \& Wang, 2020). See the fit of all the models tested, the range of factor loadings, and inter-factor correlations in Table 2.

All models had a comparably good fit (Table 2). The results of the $\chi^{2}$ difference test to compare the model fit (Table 3) of the single-factor model (MODEL A) vs the two-factor model (MODEL B) showed that the difference was significant, Scaled $\Delta$ in $-2 \mathrm{LL}=30.136, \Delta d f=1, p<.001$. Equally, comparing the 2 bi-dimensional models (MODEL C vs. MODEL B) their $\chi^{2}$ difference of was significant, Scaled $\Delta$ in $-2 \mathrm{LL}=4.821, \Delta d f=1, p<.05$. The two comparisons suggested that the two-factor model described the data better (Table 3 ). See the path diagrams of MODEL A and MODELB in Figure 2.

However, the Bifactor Model tested $\left(\chi^{2}=87.42, d f=25\right.$, RMSEA $=.055$, $\mathrm{CFI}=.962$, TLI $=.931, \mathrm{SRMR}=.035)$, had an ECV $\geq .85$, suggesting that CD-RISC10 was sufficiently unidimensional to warrant a single-factor model 
Table 3. Tests of $-2 \Delta \mathrm{LL}$ difference to compare the model fit of the alternative models A-C specified in CFA $1\left(\mathrm{n}_{\mathrm{CFA} 1}=435\right)$.

\begin{tabular}{|c|c|c|c|c|c|c|c|c|}
\hline CFA 1 Models & $\mathrm{H}_{0} \mathrm{LL}$ & $\begin{array}{l}\text { Scale } \\
\text { Factor }\end{array}$ & $\begin{array}{c}\text { Free } \\
\text { Params }\end{array}$ & $-2 \Delta \mathrm{LL}$ & $\begin{array}{l}\Delta \text { Scaling } \\
\text { Correction }\end{array}$ & $\begin{array}{l}\text { Scaled } \Delta \\
\text { in }-2 L L\end{array}$ & $\Delta d f$ & $P$ \\
\hline MODEL A & 5452.878 & 1.3720 & 35 & & & & & \\
\hline vs MODEL B & 5443.988 & 1.3950 & 34 & & & & & \\
\hline Test of Difference & & & & 17.780 & .5900 & 30.136 & 1 & .0000 \\
\hline MODEL C & -5447.589 & 1.3920 & 33 & & & & & \\
\hline vs MODEL B & -5443.988 & 1.3950 & 34 & & & & & \\
\hline Test of Difference & & & & 7.202 & 1.4940 & 4.821 & 1 & .0281 \\
\hline
\end{tabular}

Note. Estimator $=$ MLR., $\mathrm{H}_{0} \mathrm{LL}=\mathrm{Log}$ likelihood model $\left(\mathrm{H}_{0}\right)$, Scale Factor $=\mathrm{H}_{0}$ LL Scaling correction factor, Free Params $=$ Number of free parameters, Scaled $\Delta$ in $-2 \mathrm{LL}=-2 \Delta \mathrm{LL} /$ scaling correction, $\Delta d f=$ Differences of number of free parameters.
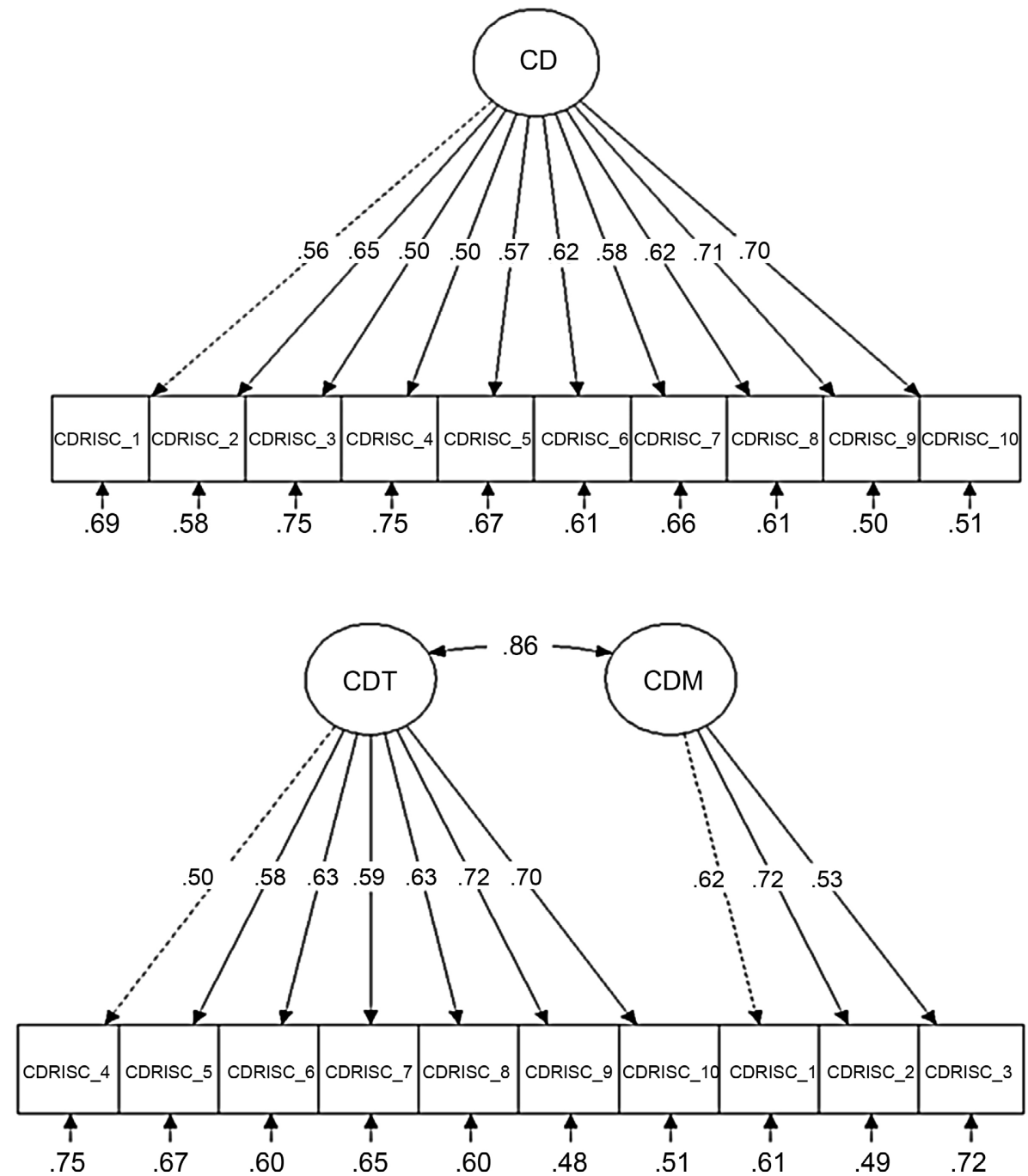

Figure 2. The path diagrams of the single-factor (upper part) and 2-factor model (lower part) specified in the CFA1 subsample $\left(40 \%, N_{\mathrm{FAl}}=435\right)$. The $\chi^{2}$ difference test $(-2 \Delta \mathrm{LL})$ to compare the model fit suggested the fit of the 2-factor model was better however the bifactor model tested to examine unidimensionality vs multidimensionality suggested the CD-RISC10 was sufficiently unidimensional. 
(Stucky et al., 2014). Additionally, PUC was < .80 (= .47), ECVGen > .60 (= .83) and $\omega_{\mathrm{h}}>.70(=.84)$, evidencing further that the presence of some multidimensionality is weak to reject the interpretation of CD-RISC10 as a primarily unidimensional measure (Reise et al., 2013). See bifactor metrics in Table 4.

Given the Bifactor results (Table 4), and considering jointly, model fit, factor loadings, inter-factor correlations (Table 2), and the $\chi^{2}$ difference tests (Table 3 ) the single-factor model fit was considered more robust, $\chi^{2}(35)=82.42$, RMSEA $=.056[90 \% \mathrm{CI} .061, .086], \mathrm{CFI}=.944, \mathrm{TLI}=.928, \mathrm{SRMR}=.045, \mathrm{BIC}=$ 11,027.26, $\mathrm{AIC}=10,945.76$. All standardized factor loadings stayed above .40 (Brown, 2015) ranging from .498 - .706, $p<.001$ (Table 2).

Subsequently, 2 trial CFAs were carried out with and without multivariate outliers to test if outliers influenced the CFA1 model fit. The comparison of the model without outliers vs. the model with outliers suggested no significant fit difference, $\triangle \mathrm{CFI}=-0.004$ and $\triangle \mathrm{RMSEA}=0.002$. See the model comparison in Table A3 in the Appendix.

\subsection{Cross-Validating Confirmatory Factor Analysis (CFA2, $n_{C F A 2}=434$ )}

The single-factor model (Model A) was crosschecked in a different subsample, of equal power $\left(\mathrm{CFA} 2, n_{\mathrm{CFA} 2}=434\right)$. The model showed good fit, $\chi^{2}(35)=115.99, \chi^{2} / d f$ $=3.31, \mathrm{RMSEA}=.073[90 \% \mathrm{CI} .061, .086], \mathrm{CFI}=.925, \mathrm{TLI}=.904, \mathrm{SRMR}=.049, \mathrm{BIC}$ $=10,713.10$, AIC $=10,632.53$. All standardized factor loadings stayed above the threshold of .40 (Brown, 2015) ranging from .510 - .732, $p<.001$ (see Figure 3). Post hoc power analysis based on the RMSEA (MacCallum et al., 1996) of the single-factor model suggested that a sample size of $n_{c f a 2}=434$ was associated with a power $>94.81 \%$ to reject a wrong model $(d f=35$, RMSEA $=.05$, alpha $=.05)$.

\subsection{Measurement Invariance across Gender}

We examined measurement invariance of the optimal single-factor model of CD-RISC10 across gender over the entire sample $(N=1089)$. When the single-factor model was tested separately for each gender $\left(N_{\text {males }}=383, N_{\text {females }}=706\right)$, it had an equally good fit for males, $\chi^{2}(35)=84.72, \chi^{2} / d f=2.42$, RMSEA $=.061$

Table 4. Additional bifactor ancillary model fit measures for the 2-factor bifactor CD-RISC10 model specified in the CFA1 and carried out in the $40 \%$ of the subsample $\left(\mathrm{n}_{\mathrm{CFAl}}=435\right)$.

\begin{tabular}{cccccc}
\hline Model Factors & ECV & Omega & $\begin{array}{c}\text { Omega } \\
\text { Hierarchical }\left(\omega_{h}\right)\end{array}$ & PUC & IECV \\
\hline Toughness & .072 & .83 & .01 & & \\
Motivation & .097 & .68 & .19 & .47 & $.45-.99$ \\
General & .83 & .87 & .84 & & \\
\hline
\end{tabular}

Note. Estimator $=$ MLR., ECV $=$ Explained Common Variance, PUC $=$ Proportion of Uncontaminated Correlations, IECV = Individual Explained Common Variance, Toughness $=$ items $5-10$ and Motivation $=$ items $1-3$, General $=$ general resilience factor. 


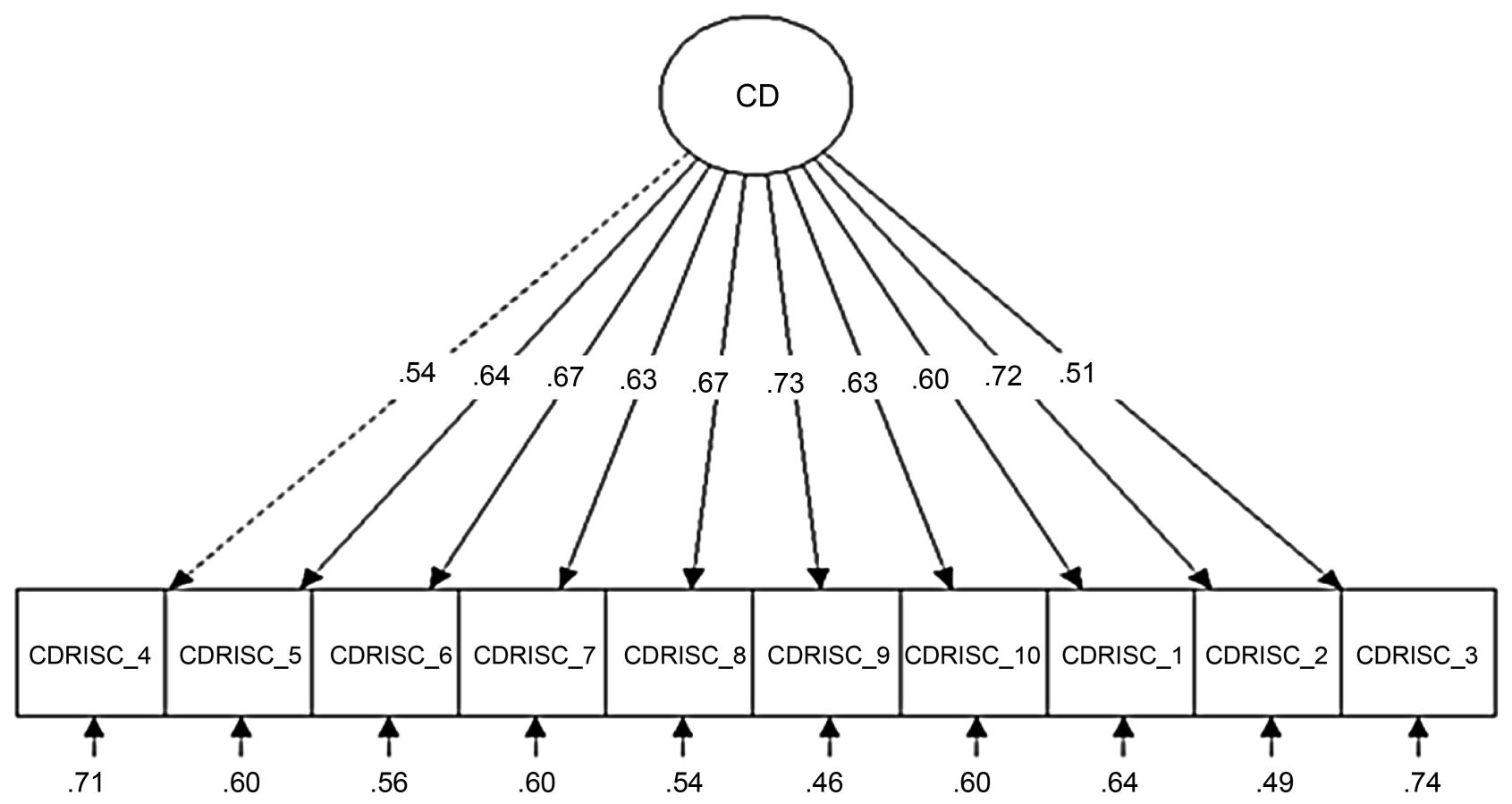

Figure 3. The path diagram of the single-factor model tested in the cross-validation CFA (CFA 2) subsample $\left(40 \%, \mathrm{~N}_{\mathrm{CFA} 2}=434\right)$.

[90\% CI .047, .075], CFI $=.945, \mathrm{TLI}=.929, \mathrm{SRMR}=.045$, and females, $\chi^{2}(35)=$ 131.87, $\chi^{2} / d f=3.77, \mathrm{RMSEA}=.063[90 \% \mathrm{CI} .053, .073], \mathrm{CFI}=.933$, TLI $=.914$, $\mathrm{SRMR}=.044$.

After, testing the configural structure (Table 5), CFI and RMSEA suggested full weak invariance (Model 2 vs 1), but not full strong (Model 3 vs 2). Therefore, to achieve partial strong invariance, the intercepts of items 1 and 9 were freely estimated and $\triangle$ RMSEA and $\triangle$ CFI values (Model 4 vs 2) suggested partial strong invariance. To achieve partial strict invariance, the error variance of item 1 was freely estimated and $\triangle$ RMSEA and $\triangle$ CFI values (Model 5 vs 4 ) indicated partial strict invariance. All model comparisons are listed in Table 5.

\subsection{Internal Consistency Reliability, Model-Based Reliability, and Convergent Validity}

All reliability coefficients were calculated over the total sample $(N=1089)$. Before calculating reliability, Model A was tested for tau-equivalency. Model A was not tau-equivalent, $F=2.503, p<0.001$. However, the CD-RISC10 items were not homogeneous, $F=2.46, p<0.001$. Therefore, using $\omega$ coefficients to estimate reliability was more appropriate. Internal consistency reliability was $\alpha=.85$ [95\% CI .84, .87] and the greatest lower bound (Jackson \& Agunwamba, 1977) was $g l b=.90>a=.85$ (see Mair, 2018). All three Composite Reliability coefficients were $\mathrm{CR}=.85>\mathrm{AVE}=.37$.

\subsection{Convergent, Discriminant Validity and Concurrent Validity with Correlation Analysis}

Bivariate correlations (Spearman rho) of the CDRISC10 were calculated to test 
Table 5. Goodness-of-Fit for the five nested CD-RISC10 models (M1 - M5) to test measurement invariance across gender $\left(\mathrm{N}_{\text {males }}=383, \mathrm{~N}_{\text {females }}=706\right)$ in the total sample $(\mathrm{N}=$ 1089).

\begin{tabular}{ccccccccc}
\hline $\begin{array}{c}\text { Nested Models } \\
\text { of Measurement } \\
\text { Invariance }\end{array}$ & $\chi^{2}$ & $d f$ & CFI & RMSEA & $\begin{array}{c}\text { Model } \\
\text { Comparison }\end{array}$ & \multicolumn{2}{c}{ Difference in fit } \\
\cline { 7 - 8 } & & & & & & & & \\
M1. Full Configural & 215.76 & 70 & .938 & .062 & - & - & - \\
M2. Full Weak & 226.24 & 79 & .937 & .059 & Model 2 vs 1 & -.001 & -.003 \\
M3. Full Strong & 258.55 & 88 & .927 & .060 & Model 3 vs 2 & -.010 & .001 \\
M4. Partial Strong & 245.86 & 87 & .932 & .058 & Model 4 vs 2 & -.005 & -.001 \\
M5. Partial Strict & 277.24 & 96 & .923 & .059 & Model 5 vs 4 & -.009 & .001 \\
\hline
\end{tabular}

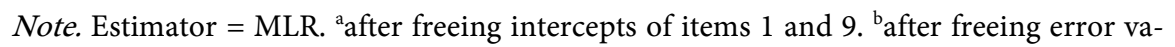
riance of item 1 .

the convergent validity with another resilience measure (BRS; Smith et al., 2008), discriminant validity with depression, anxiety and stress (DASS-9, Lovibond \& Lovibond, 1995; Yusoff, 2013; Kyriazos et al., 2018b) and concurrent validity with affectivity (SPANE-8; Diener et al., 2010; Kyriazos et al., 2018a), and life satisfaction (SWLS; Diener et al., 1985). All relationships were significant at $p<.001$, in the expected direction (Figure 4), ranging from .59 (BRS resilience) to -.37 (depression).

\subsection{Predictive Validity with a Structural Equation Model (SEM)}

Predictive validity was examined by specifying a SEM model to test the predictive power of resilience measured by CD-RISC10 on two second-order factors: 1) a second-order latent factor of Subjective Well-being (SWB; Diener et al., 1999) containing life satisfaction, (SWLS) positive and negative affect (SPANE-8) and 2) a second-order latent factor of Psychological Distress (PD) containing Anxiety, Depression, and Stress (DASS-9). This model showed a very good fit, $\chi^{2}(455)=1443.01, p=.000, \mathrm{CFI}=.921, \mathrm{TLI}=.914, \mathrm{RMSEA}=.045[90 \% \mathrm{CI}$ $=.042, .047$ ], SRMR $=.054$ (calculated with bias-corrected and accelerated CIs, MLR estimator). All measured variables had statistically significant relationships with their latent variables $(p<.001)$. The loadings of all first-order factors to SWB and PD either approximated or exceeded .70, suggesting robustness. Specifically, Life Satisfaction coefficient was $.695, p=.000$; positive affect coefficient was .766, $p=.000$; Negative affect coefficient was $-.852, p=.000$, Depression coefficient was .950, $p=.000$; Anxiety coefficient was .828, $p=.000$; and Stress coefficient was $.889, p=.000$. Crucially, the effect of resilience measured by CD-RISC10 (CD) on SWB was $\beta=.538, p<.001$, explaining $29 \%$ of the variance in SWB. The effect of resilience on PD was $\beta=-.442, p<.001$, explaining $20 \%$ of the variance in $\mathrm{PD}$. The covariance of SWB with $\mathrm{PD}$ was -.750 . Figure 5 presents the path diagram of the SEM structural model and Figure A1 in the Appendix the full SEM model. 


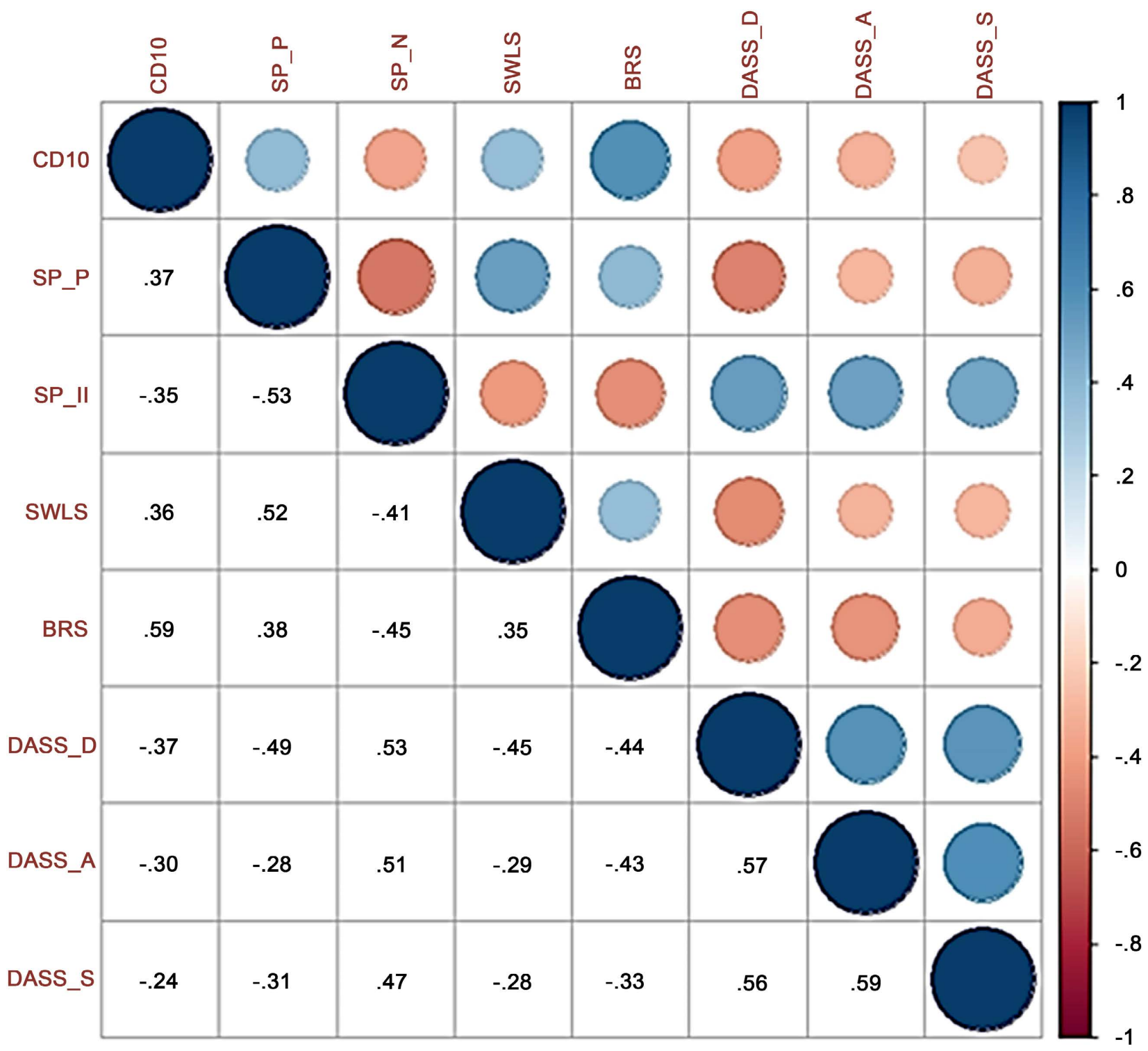

Figure 4. (1) Above the diagonal: Correlogram of the correlations (Spearman Rho) of CD-RISC10 with positive affect (SPANE-P or SP_P), negative affect (SPANE-N or SP_N), life satisfaction (SWLS), resilience (BRS), depression (DASS_D), anxiety (DASS_A) and stress (DASS_S) to evaluate convergent and discriminant validity. Positive correlations are displayed in blue and negative in red. The color intensity and the size of the colored circles are proportional to the magnitude of the correlation coefficients. The color legend in the right presents the colors corresponding to the magnitude of correlation coefficients. (2) Below the diagonal: a correlation matrix corresponding to the correlogram, with all values significant at $p<.001$.

\subsection{Normative Data and Descriptive Statistics}

CD-RISC10 score in the total sample $(N=1089)$ was $M=28(S D=6.35), M d n=$ 29, ranging from 2 - 40. On absence of normality (Shapiro-Wilk at $p<.001$ ), a Mann-Whitney-Wilcoxon test indicated that CD-RISC10 scores were significantly higher for males $(N=383, M=29.31, S D=6.21, M d n=30)$ than for females $(N=706, M=27.28, S D=6.32, M d n=28), \mathrm{W}=161,468, p=0.000$, with small effect size $(\mathrm{A}=0.60)$. Given the significant gender differences ${ }^{1}$ raw scores

${ }^{1}$ Under the restrictions of the partial scalar invariance. 
were converted to the 10th, 25th, 50th, 75th, and 90th percentiles for the total sample, and for males and females separately (Table 6). At item level, item 8 (not easily discouraged by failure) had the lowest mean $(M=2.5, S D=1.06)$ and item 5 (tend to bounce back after illness or hardship) had the highest $(M=3.08$, $S D=.85)$, equal to somewhere between scale points sometimes true (2) and often true (3). See descriptive statistics for each item in Table 6.

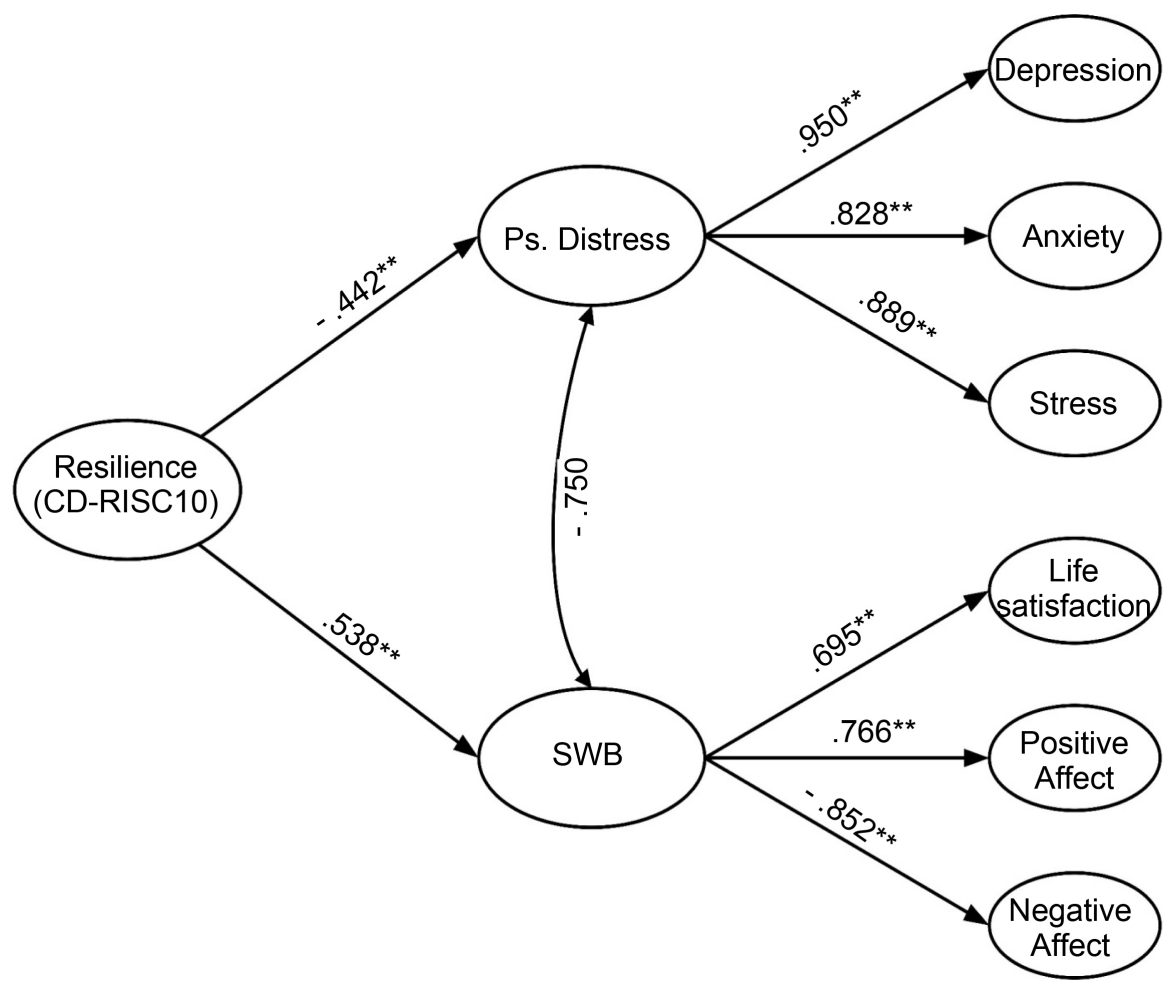

Figure 5. Path diagram with the structural paths of the higher-order SEM model to test the predictive power of resilience (CD-RISC10) on two second order factors, i.e. 1) a second-order factor of Subjective Well-being (SWB; Diener et al., 1999) comprised by life satisfaction (SWLS; Diener et al., 1985), positive and negative affect (SPANE-8; Diener et al., 2010; Kyriazos et al., 2018a) and 2) a second-order factor of psychological distress (DASS-9 Anxiety, Depression and Stress; Lovibond \& Lovibond, 1995; Kyriazos et al., 2018b). All effects were significant at $p<.001$.

Table 6. CD-RISC10 scores converted to percentiles for the total sample $(\mathrm{N}=1089)$, males $(n=303)$ and females $(n=706)$.

\begin{tabular}{ccccccccccc}
\hline & & & & & \multicolumn{5}{c}{ Percentile } \\
\cline { 6 - 10 } Group & $M d n$ & $M$ & $S D$ & Min - Max & $10^{\text {th }}$ & $25^{\text {th }}$ & $50^{\text {th }}$ & $75^{\text {th }}$ & $90^{\text {th }}$ \\
\hline $\begin{array}{c}\text { Total } \\
\text { sample }\end{array}$ & 29.00 & 28.00 & 6.35 & $2.00-40.00$ & 20.00 & 24.00 & 29.00 & 338.00 & 36.00 \\
Males & 30.00 & 29.31 & 6.21 & $2.00-40.00$ & 21.00 & 26.00 & 30.00 & 34.00 & 37.00 \\
Females & 28.00 & 27.28 & 6.32 & $4.00-40.00$ & 19.00 & 23.00 & 28.00 & 32.00 & 35.00 \\
\hline
\end{tabular}

Note. Means are unrepresentative of the sample due to the violation of normality assumption. 


\section{Discussion}

The purpose of this study was to evaluate: 1) the construct validity of the CD-RISC-10, Greek version in the general population testing alternative models and cross-validating them with a multistage process (Kyriazos, 2018a), 2) the measurement invariance across gender; 3 ) internal consistency reliability and the model-based reliability; 4) the convergent and discriminant validity; 5) the predictive validity of resilience on psychological distress and subjective well-being; 6) normative data for the entire sample, and for each gender separately.

\subsection{Interpretation and Similarity of the Findings}

To establish construct validity, we used a multistage validation (Kyriazos, 2018a), based on sample-splitting. Sample-splitting (Guadagnoli \& Velicer, 1988) is a well-known cross-validation method with factor analysis because a hypothesized structure is replicated across subsamples (Byrne, 2012; DeVellis, 2017). Given the instability of the CD-RISC10 dimensionality across samples and sometimes within the same sample (e.g. Tourunen et al., 2021; Smith et al., 2019), cross-validation was essential to safeguard structural replicability. A multistage cross-validating procedure using 3 subsamples was also implemented during CD-RISC10 development (Campbell-Sills \& Stein, 2007).

Specifically, EFA indicated a single factor, using multiple methods to select the factors to retain (Horn, 1965; Revelle \& Rocklin, 1979; Velicer, 1976). The emerging resilience factor had strong factor loadings (Costello \& Osborne, 2005; Tabachnick \& Fidell, 2013), explaining adequate total variance. This unifactorial structure was proposed by Campbell-Sills and Stein (2007).

Subsequently, two CFAs of equal sample power verified the EFA structure. In the first CFA four alternative models were specified, including a bifactor model to evaluate if CD-RISC10 was unidimensional, bidimensional, or somewhere in between (Hammer \& Toland, 2016). This procedure (although overlooked by the CD-RISC10 validation studies) is pertinent here, because bifactor models may contribute uniquely to dimensionality conflicts (Hammer \& Toland, 2016; McDermott, Levant, Hammer, Hall, McKelvey, \& Jones, 2017), although they are most popular as an alternative higher-order specification (Brown, 2015). All the CFA1 models had a comparably good fit. The fit difference test comparing the fit of all the models suggested the two-factor model fitted the data better. Nevertheless, the ancillary bifactor fit measures suggested a weak presence of bi-dimensionality to reject a unidimensional interpretation. This unidimensional structure was also proposed by many studies in the general population of Germany (Wollny \& Jacobs, 2021), Australia (Burns \& Anstey, 2010), Russia (Nartova-Bochaver et al., 2021), Slovenia (Kavčič et al., 2021) or Spain (Notario-Pacheco et al., 2011). The same was true for most studies on special populations (Gonzalez et al., 2016; Madewell \& Ponce-Garcia, 2016; Ye et al., 2017; Meng et al., 2019; Cheng et al., 2020; Blanco et al., 2019).

Further support for the robustness of the unidimensional model was the good 
model fit in the cross-validation CFA (CFA2) using a different subsample of equal power to CFA1. Note the model specified in CFA1 and CFA2 contained no error co-variances, although they would be plausible based on existing studies (Ye et al., 2017; Kavčič et al., 2021). We avoided error co-variances because this would most likely generate a solution difficult to replicate (Byrne, 2012) due to overfitting, possibly located at a local optimum. The a priori and post hoc statistical power of this model (MacCallum et al., 1996) suggested a subsample size of 1.6 times greater than the suggested minimum.

Next, we examined the measurement invariance of CD-RISC10 in the entire sample. The comparison of the nested models suggested that CD-RISC10 had fully configural and metric invariance but partial strong and strict, because items 1 and 9 were functioning differently in male and female respondents. Therefore, it is not possible to safely compare latent means across gender, since it is unknown if mean differences could be attributed to true population differences or to measurement bias (e.g. Fischer \& Karl, 2019). Similarly, studies in the Australian general population (Burns \& Anstey, 2010) also failed to establish full strong measurement invariance.

Note that male scores were significantly different and higher than female (keeping in mind the restriction of partial scalar invariance). Generally, women self-reported lower resilience than men in numerous CD-RISC10 studies (Cheng et al., 2020; Kavčič et al., 2021; Notario-Pacheco et al., 2011; Nartova-Bochaver et al., 2021). These gender differences might be attributed to some resilience qualities measured by CD-RISC10 that seem to be less pronounced in females under stress or adversity than males, e.g. internal control and personal competence (Cheng et al., 2020; Kavčič et al., 2021; Pulido-Martos et al., 2020; Taylor et al., 2000). Moreover, previous research reported higher resilience scores for adult males than females (Cheng et al., 2020; Kavčič et al., 2021; Nartova-Bochaver et al., 2021; Notario-Pacheco et al., 2011). However, for older adults, the results are inconsistent since Tourunen et al. (2021) reported no gender differences in CD-RISC10 scores an elderly from Finland but these findings were not replicated in the Chinese context (Meng et al., 2019). Therefore, normative data were calculated over the total sample and by gender. This could offer a benchmark for health professionals and numerous programs using resilience as an outcome measure.

Internal consistency reliability and all three model-based reliability estimates were equal, corroborating each other, and they stayed far above the .70 acceptability threshold (Hair et al., 2010). However, the optimal CFA1 model was not tau-equivalent, rendering alpha a somewhat undependable reliability evaluation for this 10-item measure (Brown, 2015: p. 338). In contrast, the greatest lower bound estimate managed to stay above the internal consistency reliability (Mair, 2018). Additionally, the greatest lower bound estimate was greater than the internal consistency reliability (Mair, 2018). CR was greater AVE with AVE marginally missing the .50 threshold (Fornell \& Larcker, 1981). This might be an indication that CD-RISC10 items were sufficiently reliable, however, variance due 
to construct and the variance due to error of measurement is hard to distinguish (Santos et al., 2015). The reliability (both internal consistency and model-based) were generally comparable both to the original (Campbell-Sills \& Stein, 2007) and to other studies to general populations, e.g. for a German (Wollny \& Jacobs, 2021), Russian (Nartova-Bochaver et al., 2021), or Slovenian sample (Kavčič et al., 2021).

To evaluate convergent and discriminant validity further a correlation analysis followed. All the associations were highly significant of low to strong magnitude at the expected direction, i.e. positive with resilience, life satisfaction, and PA and negative with NA and distress. The existing CD-RISC10 literature corroborates these associations (e.g. Campbell-Sills \& Stein, 2007; Wollny \& Jacobs, 2021; Nartova-Bochaver et al., 2021; Kavčič et al., 2021; Kuiper et al., 2019; Tourunen et al., 2021). In fact, a large body of quality of life research generally views wellbeing as a state of prevalence of positive psychological traits including resilience (among others). In contrast, illbeing is viewed as a state of prevalence of negative psychological traits like negative effect, stress, pessimism, or hopelessness (see Sirgy, 2021).

Furthermore, to examine the predictive effect of resilience on subjective well-being and psychological distress a SEM model specified. The direct effects of resilience on SWB (Diener et al., 1999) and on distress were significant of strong magnitude, supporting the predictive validity of resilience operationalized by CD-RISC10. Therefore, high-resilient individuals were more likely to have increased subjective well-being and decreased psychological distress than lowresilient. The above findings were consistent with existing literature on the effects of resilience on SWB (e.g. Bajaj \& Pande, 2016; Samani et al., 2007), affect (Gonzalez et al., 2016; Gucciardi et al., 2011) and distress (Campbell-Sills \& Stein, 2007; Aloba et al., 2016).

\subsection{Generalizability, Limitations, and Implications}

The generalizability of the findings is rather safe due to the rigorous cross-validation process, the alternative models tested, concrete method of model comparison, high reliability, convergent and discriminant validity, and adequate sample power. Nonetheless, the interpretation should be cautious due to the non-probability sampling, and the cross-sectional study design, disallowing causal inferences regarding the SEM model (Kline, 2020), although such rigid views on causality are rather over-simplifications with SEM (Kline, 2020; Stalikas \& Kyriazos, 2019). A limitation was the imbalanced sample in terms of gender. The study was also limited by its reliance on a monocultural sample, a single data collection procedure, and self-report measurement.

Future research directions could include measurement invariance of other demographics like age, or SES or the use of additional techniques to evidence construct validity like CFA MTMM or Multilevel CFA (see Kyriazos, 2018c; Kyriazos, 2019; Kyriazos \& Stalikas, 2019a). It would be equally interesting to fur- 
ther evaluate in the Greek context the relationship of resilience with constructs associated with well-being like meaning in life (see Stalikas, Kyriazos, Yiotsidi, \& Prassa, 2018), flourishing (e.g. Kyriazos, Stalikas, Prassa, Yotsidi, Galanakis, \& Pezirkianidis, 2018), within different contexts like interpersonal relationships (e.g. Kyriazos \& Giotsa, 2019), the COVID-19 pandemic (see Kyriazos, Galanakis, Katerelos, \& Stalikas, 2021b) or positive psychology parenting (e.g. Kyriazos \& Stalikas, 2019b; Kyriazos \& Stalikas, 2018).

\section{Conflicts of Interest}

The authors declare no conflicting interests.

\section{References}

Aloba, O., Olabisi, O., \& Aloba, T. (2016). The 10-Item Connor-Davidson Resilience Scale: Factor Structure, Reliability, Validity, and Correlates among Student Nurses in Southwestern Nigeria. Journal of the American Psychiatric Nurses Association, 22, 43-51. https://doi.org/10.1177/1078390316629971

Aswini, S., \& Deb, A. (2019). Connor Davidson Resilience Scale and Flourishing Scale: Translation and Cultural Adaptation in Malayalam. Journal of Psychosocial Research, 14, 275-283. https://doi.org/10.32381/JPR.2019.14.02.4

Bajaj, B., \& Pande, N. (2016). Mediating Role of Resilience in the Impact of Mindfulness on Life Satisfaction and Affect as Indices of Subjective Wellbeing. Personality and Individual Differences, 93, 63-67. https://doi.org/10.1016/j.paid.2015.09.005

Bentler, P. M. (1972). A Lower-Bound Method for the Dimension-Free Measurement of Internal Consistency. Social Science Research, 1, 343-357. https://doi.org/10.1016/0049-089X(72)90082-8

Bentler, P. M. (2009). Alpha, Dimension-Free, and Model-Based Internal Consistency Reliability. Psychometrika, 74, 137-143. https://doi.org/10.1007/s11336-008-9100-1

Blanco, V., Guisande, M. A., Sánchez, M. T., Otero, P., \& Vázquez, F. L. (2019). Spanish Validation of the 10-Item Connor-Davidson Resilience Scale (CD-RISC 10) with NonProfessional Caregivers. Aging \& Mental Health, 23, 183-188. https://doi.org/10.1080/13607863.2017.1399340

Bollen, K. A. (1980). Issues in the Comparative Measurement of Political Democracy. American Sociological Review, 45, 370-390. https://doi.org/10.2307/2095172

Brown, T. A. (2015). Confirmatory Factor Analysis for Applied Research. Guilford Publications.

Burns, R. A., \& Anstey, K. J. (2010). The Connor-Davidson Resilience Scale (CD-RISC): Testing the Invariance of a Unidimensional Resilience Measure That Is Independent of Positive and Negative Affect. Personality and Individual Differences, 48, 527-531. https://doi.org/10.1016/j.paid.2009.11.026

Byrne, B. M. (2012). Structural Equation Modeling with Mplus: Basic Concepts, Applications, and Programming. Routledge. https://doi.org/10.4324/9780203807644

Campbell-Sills, L., \& Stein, M. B. (2007). Psychometric Analysis and Refinement of the Connor-Davidson Resilience Scale (CD-RISC): Validation of a 10-Item Measure of Resilience. Journal of Traumatic Stress, 20, 1019-1028. https://doi.org/10.1002/jts.20271

Campbell-Sills, L., Forde, D. R., \& Stein, M. B. (2009). Demographic and Childhood Environmental Predictors of Resilience in a Community Sample. Journal of Psychiatric 
Research, 43, 1007-1012. https://doi.org/10.1016/j.jpsychires.2009.01.013

Carmines, E. G., \& McIver, J. D. (1981). Analyzing Models with Unobserved Variables: Analysis of Covariance Structures. In G. W. Bohinstedt, \& E. F. Borgatta (Eds.), Social Measurement: Current Issues (pp. 65-115). Sage.

Chen, F. F. (2007). Sensitivity of Goodness of Fit Indexes to Lack of Measurement Invariance. Structural Equation Modeling, 14, 464-504. https://doi.org/10.1080/10705510701301834

Cheng, C., Dong, D., He, J., Zhong, X., \& Yao, S. (2020). Psychometric Properties of the 10-Item Connor-Davidson Resilience Scale (CDRISC-10) in Chinese Undergraduates and Depressive Patients. Journal of Affective Disorders, 261, 211-220. https://doi.org/10.1016/j.jad.2019.10.018

Cheung, G. W., \& Rensvold, R. B. (2002). Evaluating Goodness-of-Fit Indexes for Testing Measurement Invariance. Structural Equation Modeling, 9, 233-255. https://doi.org/10.1207/S15328007SEM0902_5

Connor, K. M., \& Davidson, J. R. T. (2003). Development of a New Resilience Scale: The Connor-Davidson Resilience Scale (CD-RISC). Depression and Anxiety, 18, 76-82. https://doi.org/10.1002/da.10113

Costello, A. B., \& Osborne, J. (2005). Best Practices in Exploratory Factor Analysis: Four Recommendations for Getting the Most from Your Analysis. Practical Assessment Research \& Evaluation, 10, 1-9.

DeVellis, R. F. (2017). Scale Development: Theory and Applications (4th ed.). Sage.

Diener, E., Emmons, R. A., Larsen, R. J., \& Griffin, S. (1985). The Satisfaction with Life Scale. Journal of Personality Assessment, 49, 71-75. https://doi.org/10.1207/s15327752jpa4901_13

Diener, E., Suh, E. M., Lucas, R. E., \& Smith, H. L. (1999). Subjective Well-Being: Three Decades of Progress. Psychological Bulletin, 125, 276-302.

https://doi.org/10.1037/0033-2909.125.2.276

Diener, E., Wirtz, D., Tov, W., Kim-Prieto, C., Choi, D, Oishi, S., \& Biswas-Diener, R. (2010). New Well-Being Measures: Short Scales to Assess Flourishing and Positive and Negative Feelings. Social Indicators Research, 97, 143-156. https://doi.org/10.1007/s11205-009-9493-y

Fischer, R., \& Karl, J. A. (2019). A Primer to (Cross-Cultural) Multi-Group Invariance Testing Possibilities in R. Frontiers in Psychology, 10, 1507. https://doi.org/10.3389/fpsyg.2019.01507

Fornell, C., \& Larcker, D. F. (1981). Structural Equation Models with Unobservable Variables and Measurement Error: Algebra and Statistics. Journal of Marketing Research, 18, 382-388. https://doi.org/10.1177/002224378101800313

Gadermann, A. M., Guhn, M., \& Zumbo, B. D. (2012). Estimating Ordinal Reliability for Likert-Type and Ordinal Item Response Data: A Conceptual, Empirical, and Practical Guide. Practical Assessment, Research \& Evaluation, 17, 1-13.

Gonzalez, S. P., Moore, E. W. G., Newton, M., \& Galli, N. A. (2016). Validity and Reliability of the Connor-Davidson Resilience Scale (CD-RISC) in Competitive Sport. Psychology of Sport and Exercise, 23, 31-39. https://doi.org/10.1016/j.psychsport.2015.10.005

Guadagnoli, E., \& Velicer, W. F. (1988). Relation to Sample Size to the Stability of Component Patterns. Psychological Bulletin, 103, 265-275.

https://doi.org/10.1037/0033-2909.103.2.265

Guarnizo Guzmán, C. P., García Martín, M. B., Suárez Falcón, J. C., \& Sierra, M. A. 
(2019). Psychometric Properties of the Connor Davidson Resilience Scale (CD-RISC) on Vulnerable Colombian Adolescents. International Journal of Psychology \& Psychological Therapy, 19, 277-289.

Gucciardi, D. F., Jackson, B., Coulter, T. J., \& Mallett, C. J. (2011). The Connor-Davidson Resilience Scale (CD-RISC): Dimensionality and Age-Related Measurement Invariance with Australian Cricketers. Psychology of Sport and Exercise, 12, 423-433. https://doi.org/10.1016/j.psychsport.2011.02.005

Hair, J., Black, W., Babin, B., \& Anderson, R. (2010). Multivariate Data Analysis (7th ed.). Prentice-Hall, Inc.

Hammer, J. H., \& Toland, M. D. (2016). Bifactor Analysis in Mplus. University of Kentucky. http://sites.education.uky.edu/apslab/upcoming-events/

Hoque, A. S., Awang, Z., Jusoff, K., Salleh, F., \& Muda, H. (2017). Social Business Efficiency: Instrument Development and Validation Procedure Using Structural Equation Modeling. International Business Management, 11, 222-231.

Horn, J. L. (1965). A Rationale and Test for the Number of Factors in Factor Analysis. Psychometrika, 30, 179-185. https://doi.org/10.1007/BF02289447

Hu, L., \& Bentler, P. M. (1999). Cutoff Criteria for Fit Indexes in Covariance Structure Analysis: Conventional Criteria versus New Alternatives. Structural Equation Modeling, 6, 1-55. https://doi.org/10.1080/10705519909540118

Hu, T., Zhang, D., \& Wang, J. (2015). A Meta-Analysis of the Trait Resilience and Mental Health. Personality and Individual Differences, 76, 18-27. https://doi.org/10.1016/j.paid.2014.11.039

Jackson, P., \& Agunwamba, C. (1977). Lower Bounds for the Reliability of the Total Score on a Test Composed of Non-Homogeneous Items: I: Algebraic Lower Bounds. Psychometrika, 42, 567-578. https://doi.org/10.1007/BF02295979

Kavčič, T., Kocjan, G. Z. \& Dolenc, P. (2021). Measurement Invariance of the CDRISC-10 across Gender, Age, and Education: A Study with Slovenian Adults. Current Psychology. https://doi.org/10.1007/s12144-021-01564-3

Kelley, T. L. (1935). Essential Traits of Mental Life, Harvard Studies in Education (Vol. 26). Harvard University Press.

Kline, R. B. (2016). Principles and Practice of Structural Equation Modeling (4th ed.). The Guilford Press.

Kline, R. B. (2020). Becoming a Behavioral Science Researcher (2nd ed.). Guilford Press.

Kuiper, H., van Leeuwen, C. C., Stolwijk-Swüste, J. M., \& Post, M. W. (2019). Measuring Resilience with the Connor-Davidson Resilience Scale (CD-RISC): Which Version to Choose? Spinal Cord, 57, 360-366. https://doi.org/10.1038/s41393-019-0240-1

Kyriazos, T. (2017). Reliability of Psychometric Instruments. In M. Galanakis, C. Pezirkianidis, \& A. Stalikas (Eds.), Basic Aspects of Psychometrics (pp. 85-126). Topos.

Kyriazos, T. A. (2018a). Applied Psychometrics: The 3-Faced Construct Validation Method, a Routine for Evaluating a Factor Structure. Psychology, 9, 2044-2072. https://doi.org/10.4236/psych.2018.98117

Kyriazos, T. A. (2018b). Applied Psychometrics: Writing-Up a Factor Analysis Construct Validation Study with Examples. Psychology, 9, 2503-2530. https://doi.org/10.4236/psych.2018.911144

Kyriazos, T. A. (2018c). Applied Psychometrics: The Application of CFA to Multitrait-Multimethod Matrices (CFA-MTMM). Psychology, 9, 2625-2648.

https://doi.org/10.4236/psych.2018.912150

Kyriazos, T. A. (2019). Applied Psychometrics: The Modeling Possibilities of Multilevel 
Confirmatory Factor Analysis (MLV CFA). Psychology, 10, 777-798.

https://doi.org/10.4236/psych.2019.106051

Kyriazos, T. A., \& Stalikas, A. (2018). Positive Parenting or Positive Psychology Parenting? Towards a Conceptual Framework of Positive Psychology Parenting. Psychology, 9, 1761-1788. https://doi.org/10.4236/psych.2018.97104

Kyriazos, T. A., \& Stalikas, A. (2019a). Alabama Parenting Questionnaire-Short Form (APQ-9): Evidencing Construct Validity with Factor Analysis, CFA MTMM and Measurement Invariance in a Greek Sample. Psychology, 10, 1790-1817. https://doi.org/10.4236/psych.2019.1012117

Kyriazos, T. A., \& Stalikas, A. (2019b). Nicomachus-Positive Parenting (NPP): Development and Initial Validation of a Parenting Questionnaire within the Positive Psychology Framework. Psychology, 10, 2115-2165. https://doi.org/10.4236/psych.2019.1015136

Kyriazos, T. A., \& Giotsa, A. (2019). Interpersonal Rejection Anxiety Questionnaire (IRAQ): Psychometric Properties of the Greek Version. Psychology, 10, 1542-1563. https://doi.org/10.4236/psych.2019.1011101

Kyriazos, T. A., Stalikas, A., Prassa, K., \& Yotsidi, V. (2018a). A 3-Faced Construct Validation and a Bifactor Subjective Well-Being Model Using the Scale of Positive and Negative Experience, Greek Version. Psychology, 9, 1143-1175.

https://doi.org/10.4236/psych.2018.95071

Kyriazos, T. A., Stalikas, A., Prassa, K., \& Yotsidi, V. (2018b). Can the Depression Anxiety Stress Scales Short Be Shorter? Factor Structure and Measurement Invariance of DASS-21 and DASS-9 in a Greek, Non-Clinical Sample. Psychology, 9, 1095-1127. https://doi.org/10.4236/psych.2018.95069

Kyriazos, T. A., Stalikas, A., Prassa, K., Galanakis, M., Yotsidi, V., \& Lakioti, A. (2018). Psychometric Evidence of the Brief Resilience Scale (BRS) and Modeling Distinctiveness of Resilience from Depression and Stress. Psychology, 9, 1828-1857. https://doi.org/10.4236/psych.2018.97107

Kyriazos, T. A., Stalikas, A., Prassa, K., Yotsidi, V., Galanakis, M., \& Pezirkianidis, C. (2018). Validation of the Flourishing Scale (FS), Greek Version and Evaluation of Two Well-Being Models. Psychology, 9, 1789-1813. https://doi.org/10.4236/psych.2018.97105

Kyriazos, T., Galanakis, M., Karakasidou, E., \& Stalikas, A. (2021a). Well-Being Implications of the COVID-19 Quarantine Using Machine Learning: Are Creative Activities a Ubiquitous Classifier? Personality and Individual Differences, 181, Article ID: 110980. https://doi.org/10.1016/j.paid.2021.110980

Kyriazos, T., Galanakis, M., Katerelos, I., \& Stalikas, A. (2021b). Does the Pollyannaish View on Life Hold during Early COVID-19 Quarantine? Modeling the Effects of Positive Emotions, Hope, Optimism and Life Meaning on Life Satisfaction. Open Journal of Social Sciences, 9, 315-338. https://doi.org/10.4236/jss.2021.910023

Levey, E. J., Rondon, M. B., Sanchez, S., Williams, M. A., \& Gelaye, B. (2021). Psychometric Properties of the Spanish Version of the 10-Item Connor Davidson Resilience Scale (CD-RISC) among Adolescent Mothers in Peru. Journal of Child \& Adolescent Trauma, 14, 29-40. https://doi.org/10.1007/s40653-019-00295-9

Li, C. (2016). Confirmatory Factor Analysis with Ordinal Data: Comparing Robust Maximum Likelihood and Diagonally Weighted Least Squares. Behavior Research Methods volume, 48, 936-949. https://doi.org/10.3758/s13428-015-0619-7

Lovibond, S. H., \& Lovibond, P. F. (1995). Manual for the Depression Anxiety Stress Scales. Psychology Foundation. https://doi.org/10.1037/t01004-000 
MacCallum, R. C., Browne, M. W., \& Sugawara, H. M. (1996). Power Analysis and Determination of Sample Size for Covariance Structure Modeling. Psychological Methods, 1, 130-149. https://doi.org/10.1037/1082-989X.1.2.130

Madewell, A. N., \& Ponce-Garcia, E. (2016). Assessing Resilience in Emerging Adulthood: The Resilience Scale (RS), Connor-Davidson Resilience Scale (CD-RISC), and Scale of Protective Factors (SPF). Personality and Individual Differences, 97, 249-255. https://doi.org/10.1016/j.paid.2016.03.036

Mair, P. (2018). Modern Psychometrics with R. Springer International. https://doi.org/10.1007/978-3-319-93177-7

McDermott, R. C., Levant, R., Hammer, J. H., Hall, R. J., McKelvey, D. K., \& Jones, Z. (2017). Further Examination of the Factor Structure of the Male Role Norms Inventory-Short Form (MRNI-SF): Measurement Considerations for Women, Men of Color, and Gay Men. Journal of Counseling Psychology, 64, 724-738. https://doi.org/10.1037/cou0000225

McDonald, R. P. (1999). Test Theory: A Unified Treatment. Erlbaum.

Meng, M., He, J., Guan, Y., Zhao, H., Yi, J., Yao, S., \& Li, L. (2019). Factorial Invariance of the 10-Item Connor-Davidson Resilience Scale across Gender among Chinese Elders. Frontiers in Psychology, 10, 1237. https://doi.org/10.3389/fpsyg.2019.01237

Nartova-Bochaver, S., Korneev, A., \& Bochaver, K. (2021). Validation of the 10-Item Connor-Davidson Resilience Scale: The Case of Russian Youth. Frontiers in Psychiatry, 12, Article ID: 611026. https://doi.org/10.3389/fpsyt.2021.611026

Notario-Pacheco, B., Solera-Martínez, M., Serrano-Parra, M. D., Bartolomé-Gutiérrez, R., García-Campayo, J., \& MartínezVizcaíno, V. (2011). Reliability and Validity of the Spanish Version of the 10-Item Connor-Davidson Resilience Scale (10-Item CDRISC) in Young Adults. Health and Quality of Life Outcomes, 9, Article No. 63. https://doi.org/10.1186/1477-7525-9-63

Pulido-Martos, M., Fernández-Sánchez, M. D., \& Lopez-Zafra, E. (2020). Measurement Invariance across Gender and Age in the Connor-Davidson Resilience Scale (CD-RISC) in a Spanish General Population. Quality of Life Research, 29, 1373-1384. https://doi.org/10.1007/s11136-019-02389-1

R Development Core Team (2021). R: A Language and Environment for Statistical Computing. R Foundation for Statistical Computing.

Rahimi, B., Baetz, M., Bowen, R., \& Balbuena, L. (2014). Resilience, Stress, and Coping among Canadian Medical Students. Canadian Medical Education Journal, 5, e5-e12. https://doi.org/10.36834/cmej.36689

Raykov, T. (2004). Behavioral Scale Reliability and Measurement Invariance Evaluation Using Latent Variable Modeling. Behavior Therapy, 35, 299-331. https://doi.org/10.1016/S0005-7894(04)80041-8

Raykov, T. (2012). Scale Construction and Development Using Structural Equation Modeling. In R. H. Hoyle (Ed.), Handbook of Structural Equation Modeling (pp. 472-492). Guildford Press.

Reise, S. P., Bonifay, W. E., \& Haviland, M. G. (2013). Scoring and Modeling Psychological Measures in the Presence of Multidimensionality. Journal of Personality Assessment, 95, 129-140. https://doi.org/10.1080/00223891.2012.725437

Revelle, W., \& Rocklin, T. (1979). Very Simple Structure: An Alternative Procedure for Estimating the Optimal Number of Interpretable Factors. Multivariate Behavioral Research, 14, 403-414. https://doi.org/10.1207/s15327906mbr1404_2

Rigdon, E. E. (1998). Structural Equation Modeling. In G. A. Marcoulides (Ed.), Modern Methods for Business Research (pp. 251-294). Mahwah, NJ: Erlbaum. 
Salisu, I., \& Hashim, N. (2017). Critical Review of Scales Used in Resilience Research. IOSR Journal of Business and Management, 19, 23-33. https://doi.org/10.9790/487X-1904032333

Samani, S., Jokar, B., \& Sahragard, N. (2007). Effects of Resilience on Mental Health and Life Satisfaction. Iranian Journal of Psychiatry and Clinical Psychology, 13, 290-295.

Santos, N. C., Costa, P. S., Amorim, L., Moreira, P. S., Cunha, P., Cotter, J. et al. (2015) Exploring the Factor Structure of Neurocognitive Measures in Older Individuals. PLoS ONE, 10, e0124229. https://doi.org/10.1371/journal.pone.0124229

Satorra, A., \& Bentler, P. M. (2010). Ensuring Positiveness of the Scaled Difference Chi-Square Test Statistic. Psychometrika, 75, 243-248.

https://doi.org/10.1007/s11336-009-9135-y

Seligman, M. E. P. (2011). Flourish: A New Understanding of Happiness and Wellbeing and How to Achieve Them. Nicholas Brealey.

Singh, K., Junnarkar, M., \& Kaur, J. (2016). Measures of Positive Psychology: Development and Validation. Springer. https://doi.org/10.1007/978-81-322-3631-3

Sirgy, M. J. (2021). The Psychology of Quality of Life: Wellbeing and Positive Mental Health (3rd ed.). Springer Nature Switzerland AG. https://doi.org/10.1007/978-3-030-71888-6

Smith, B. W., Dalen, J., Wiggins, K., Tooley, E., Christopher, P., \& Bernard, J. (2008). The Brief Resilience Scale: Assessing the Ability to Bounce Back. International Journal of Behavioral Medicine, 15, 194-200. https://doi.org/10.1080/10705500802222972

Smith, K. J., Emerson, D. J., \& Schuldt, M. A. (2018). A Demographic and Psychometric Assessment of the Connor-Davidson Resilience Scale 10 (CD-RISC 10) with a U.S. Public Accounting Sample. Journal of Accounting \& Organizational Change, 14, 513-534. https://doi.org/10.1108/JAOC-12-2016-0085

Smith, K. J., Emerson, D. J., Haight, T. D., Mauldin, S., \& Wood, B. G. (2019). An Examination of the Psychometric Properties of the Connor Davidson Resilience Scale-10 (CD-RISC10) among Accounting and Business Students. Journal of Accounting Education, 47, 48-62. https://doi.org/10.1016/j.jaccedu.2019.01.002

Stalikas, A., \& Kyriazos, T. (2019). Research Methods and Statistics Using R. Topos.

Stalikas, A., Kyriazos, T. A., Yotsidi, V., \& Prassa, K. (2018). Using Bifactor EFA, Bifactor CFA and Exploratory Structural Equation Modeling to Validate Factor Structure of the Meaning in Life Questionnaire, Greek Version. Psychology, 9, 348-371. https://doi.org/10.4236/psych.2018.93022

Stucky, B. D., Edelen, M. O., Vaughan, C. A., Tucker, J. S., \& Butler, J. (2014). The Psychometric Development and Initial Validation of the DCI-A Short Form for Adolescent Therapeutic Community Treatment Process. Journal of Substance Abuse Treatment, 46, 516-521. https://doi.org/10.1016/j.jsat.2013.12.005

Tabachnick, B. G., \& Fidell, L. S. (2013). Using Multivariate Statistics (6th ed.). Allyn \& Bacon.

Taylor, S., Klein, L., Lewis, B., Grunewald, T., Gurung, R., \& Updergraff, J. (2000). Biobehavioural Responses to Stress in Females: Tend and Befriend, Not Fight or Flight. Psychological Review, 107, 411-429. https://doi.org/10.1037/0033-295X.107.3.411

Tourunen, A., Siltanen, S., Saajanaho, M., Koivunen, K., Kokko, K., \& Rantanen, T. (2021) Psychometric Properties of the 10-Item Connor-Davidson Resilience Scale among Finnish Older Adults. Aging \& Mental Health, 25, 99-106.

https://doi.org/10.1080/13607863.2019.1683812

Vaishnavi, S., Connor, K., \& Davidson, J. R. (2007). An Abbreviated Version of the Con- 
nor-Davidson Resilience Scale (CD-RISC), the CD-RISC2: Psychometric Properties and Applications in Psychopharmacological Trials. Psychiatry Research, 152, 293-297. https://doi.org/10.1016/j.psychres.2007.01.006

Vargha, A., \& Delaney, H. D. (2000). A Critique and Improvement of the CL Common Language Effect Size Statistics of McGraw and Wong. Journal of Educational and Behavioral Statistics, 25, 101-132. https://doi.org/10.3102/10769986025002101

Velicer, W. F. (1976). Determining the Number of Components from the Matrix of Partial Correlations. Psychometrika, 41, 321-327. https://doi.org/10.1007/BF02293557

Wang, J., \& Wang, X. (2020). Structural Equation Modeling (2nd ed.). Wiley, Higher Education Press.

Werts, C. E., Linn, R. N., \& Karl, G. J. (1974). Interclass Reliability Estimates: Testing Structural Assumptions. Educational and Psychological Measurement, 34, 25-33. https://doi.org/10.1177/001316447403400104

Windle, G., Bennett, K., \& Noyes, J. (2011). A Methodological Review of Resilience Measurement Scales. Health and Quality of Life Outcomes, 9, Article No. 8. https://doi.org/10.1186/1477-7525-9-8

Wollny, A. I., \& Jacobs, I. (2021). Validity and Reliability of the German Versions of the CD-RISC-10 and CD-RISC-2. Current Psychology. https://doi.org/10.1007/s12144-021-01670-2

Ye, Z. J., Qiu, H. Z., Li, P. F., Chen, P., Liang, M. Z., Liu, M. L., Yu, Y. L., Wang, S. N., \& Quan, X. M. (2017). Validation and Application of the Chinese Version of the 10-Item Connor-Davidson Resilience Scale (CD-RISC-10) among Parents of Children with Cancer Diagnosis. European Journal of Oncology Nursing, 27, 36-44. https://doi.org/10.1016/j.ejon.2017.01.004

Yusoff, M. S. B. (2013). Psychometric Properties of the Depression Anxiety Stress Scale in a Sample of Medical Degree Applicants. International Medical Journal, 20, 295-300. 


\section{Appendix}

Table A1. Description of the analyses sequence performed.

\begin{tabular}{|c|c|c|}
\hline N. & Description & Rationale \\
\hline 1 & Data screening & To detect outliers with Mahalanobis distance critical value. \\
\hline 2 & $\begin{array}{l}\text { Univariate normality evaluation } \\
\text { with multiple tests }\end{array}$ & $\begin{array}{l}\text { To test for skewness, kurtosis and the univariate normality assumption } \\
\text { with Kolmogorov-Smirnov (Lilliefors), Shapiro-Wilk, Shapiro-Francia, } \\
\text { and Anderson-Darling tests. }\end{array}$ \\
\hline 3 & $\begin{array}{l}\text { Multivariate normality evaluation with } \\
\text { multiple tests }\end{array}$ & $\begin{array}{l}\text { To test for the multivariate normality assumption with Mardia's } \\
\text { multivariate kurtosis and multivariate skewness tests, Henze-Zirkler's } \\
\text { consistent test, Doornik-Hansen omnibus test, } \\
\text { Energy test and Royston test. }\end{array}$ \\
\hline 4 & Sample-splitting $(20 \%, 40 \%, 40 \%)$ & $\begin{array}{l}\text { To carry out EFA (20\%), an initial CFA1 ( } 40 \%) \text { and cross-validating } \\
\text { CFA2 ( } 40 \%) \text { in three different subsamples, the sample was randomly } \\
\text { divided into three parts }(20 \%, 40 \%, 40 \%) \text {. The two CFA subsamples } \\
\text { ( } 40 \%) \text { were of equal power (3-Faced Construct Validation Method, } \\
\text { Kyriazos, 2018a). }\end{array}$ \\
\hline 5 & Exploratory Factor Analysis (EFA) & $\begin{array}{l}\text { To establish a structure for CD-RISC10. The number of factors to re- } \\
\text { tain was examined with Parallel Analysis (Horn, 1965), Very Simple } \\
\text { Structure (Revelle \& Rocklin, 1979), Minimum Average Partial } \\
\text { Correlations (Velicer, 1976) and Bayesian information criterion (BIC). }\end{array}$ \\
\hline 6 & $\begin{array}{l}\text { Confirm the EFA results with a } \\
\text { Confirmatory Factor Analysis (CFA 1) }\end{array}$ & $\begin{array}{l}\text { The EFA structure of CD-RISC10 was confirmed with an initial CFA, } \\
\text { to test alternative models including a bifactor model. }\end{array}$ \\
\hline 7 & Tests of fit difference & $\begin{array}{l}\text { To compare the model fit of all the alternative CFA } 1 \text { models } \\
\text { with the likelihood ratio test ( }-2 \Delta L L \text { MLR rescaled version; } \\
\text { Satorra \& Bentler, 2010). }\end{array}$ \\
\hline 8 & Evaluating the Bifactor model & $\begin{array}{l}\text { To evaluate the bifactor model, using bifactor ancillary model fit } \\
\text { measures (Reise, Bonifay, \& Haviland, 2013). }\end{array}$ \\
\hline 9 & $\begin{array}{l}\text { Evaluating the influence of } \\
\text { outliers on CFA1 }\end{array}$ & $\begin{array}{l}\text { To test if outliers influenced CFA } 1 \text { model fit with } 2 \text { trial CFAs } \\
\text { (in a subsample with vs without multivariate outliers; } \\
\text { Tabachnick \& Fidell, 2013). }\end{array}$ \\
\hline 10 & $\begin{array}{l}\text { Cross-validating the CFA1 optimal } \\
\text { model with CFA2 }\end{array}$ & $\begin{array}{l}\text { To cross-validate the optimal CFA1 in a different subsample } \\
\text { of equal power (CFA2). }\end{array}$ \\
\hline 11 & $\begin{array}{l}\text { A priori \& post hoc power analysis } \\
\text { of the CFA } 2 \text { model }\end{array}$ & $\begin{array}{l}\text { To evaluate the sample required for achieving a power of } 80 \% \text { to reject } \\
\text { a wrong model. An alpha level of } .05 \text { was assumed with an RMSEA } \\
\text { misspecification of } .05 \text { (MacCallum, Browne, \& Sugawara, 1996). }\end{array}$ \\
\hline 12 & $\begin{array}{l}\text { Measurement invariance across gender } \\
\text { to the strict level of the CFA } 2 \text { model }\end{array}$ & $\begin{array}{l}\text { To test if the cross-validated CFA } 2 \text { model was invariant factors, } \\
\text { factor loadings, intercepts, and error variances across gender. }\end{array}$ \\
\hline 13 & $\begin{array}{l}\text { Internal Consistency Reliability, } \\
\text { Model-Based Reliability and Model-based } \\
\text { Convergent Validity after testing } \\
\text { tau-equivalency of the optimal model }\end{array}$ & $\begin{array}{l}\text { To evaluate Cronbach's alpha [95\% CI], and the greatest lower bound } \\
\text { estimate ( } \mathrm{glb} \text {; Jackson \& Agunwamba, 1977). To evaluate Composite } \\
\text { Reliability (CR; Werts, Linn, \& Karl, 1974) with the standardized load- } \\
\text { ings using } 3 \text { calculations (Bollen, 1980; Bentler, 1972; McDonald, 1999) } \\
\text { and Average Variance Extracted (AVE; Fornell \& Larcker, 1981), evi- } \\
\text { dencing model-based reliability (see Mair, 2018) and convergent valid- } \\
\text { ity respectively (see Hoque et al., 2017). }\end{array}$ \\
\hline
\end{tabular}




\section{Continued}

14

Convergent, Discriminant Validity with correlation analysis

15

Predictive Validity with a Structural Equation Model (SEM)

16

Differences in resilience across males and females
To test Convergent and Discriminant Validity with other constructs Spearman's rho correlation coefficient was estimated. An alpha level of .01 was assumed.

To test the predictive power of resilience operationalized with CD-RISC10 on two second-order factors: (1) Subjective Well-being (Diener et al., 1999) and (2) Psychological Distress (Lovibond \& Lovibond, 1995; Kyriazos et al., 2018b).

To test if there are differences in resilience across gender a Mann-Whitney-Wilcoxon test was calculated. The effect size was calculated with Vargha and Delaney (2000) interpretation (A estimate), assuming an alpha level of .01.

To convert raw scores to percentiles for the total sample and for males-females separately.

Note. Data was analysed with R software.

Table A2. Item descriptive statistics, univariate and multivariate normality tests for the total sample $(\mathrm{N}=1089)$ and the 3 subsamples $\left(n_{\mathrm{EFA}}=20 \%, n_{\mathrm{CFA} 1}=40 \%\right.$ and $\left.n_{\mathrm{CFA} 2}=40 \%\right)$ for CD-RISC 10 .

\begin{tabular}{|c|c|c|c|c|c|c|c|c|}
\hline \multirow{2}{*}{ ITEM } & \multicolumn{4}{|c|}{ Descriptive Statistics } & \multicolumn{4}{|c|}{ Univariate Normality Tests } \\
\hline & $M$ & $S D$ & Skew & Kurtosis & $\mathrm{KS}^{*}$ & $\mathrm{SW}^{\star}$ & $\mathrm{SF}^{*}$ & $\mathrm{AD}^{*}$ \\
\hline ITEM 1 & 2.98 & .89 & -.76 & .45 & .26 & .84 & .84 & 66.79 \\
\hline ITEM 2 & 2.76 & .87 & -.46 & .14 & .25 & .87 & .87 & 61.47 \\
\hline ITEM 3 & 2.72 & 1.10 & -.59 & -.33 & .21 & .88 & .88 & 48.21 \\
\hline ITEM 4 & 2.57 & 1.07 & -.56 & -.20 & .23 & .89 & .89 & 46.62 \\
\hline ITEM 5 & 3.08 & .85 & -.75 & .30 & .24 & .83 & .83 & 73.06 \\
\hline ITEM 6 & 2.97 & .80 & -.63 & .56 & .27 & .84 & .83 & 75.02 \\
\hline ITEM 7 & 2.76 & 1.04 & -.74 & .11 & .25 & .87 & .84 & 54.38 \\
\hline ITEM 8 & 2.50 & 1.06 & -.45 & -.40 & .23 & .90 & .87 & 45.97 \\
\hline ITEM 9 & 2.98 & .96 & -.83 & .31 & .24 & .84 & .90 & 64.76 \\
\hline ITEM 10 & 2.67 & 1.00 & -.53 & -.09 & .23 & .88 & .84 & 49.50 \\
\hline \multicolumn{9}{|c|}{ Multivariate Normality Tests } \\
\hline Sample & $\begin{array}{c}\text { Multi-variate } \\
\text { Outliers }^{\mathrm{a}}\end{array}$ & M-Skew* & M-Kurtosis ${ }^{*}$ & Henze-Zirkle & $\mathrm{er}^{*}$ & $\begin{array}{l}\text { Doornik-Hansen } \\
\qquad(d f)^{\star}\end{array}$ & Energy ${ }^{*}$ & Royston* \\
\hline Total $(N=1089)$ & 32 & 1361.04 & 4.00 & 2.29 & & $495.30(20)$ & 1.89 & 1325.10 \\
\hline $\operatorname{EFA}\left(n_{\mathrm{EFA}}=220\right)$ & 3 & 467.02 & 9.51 & 1.17 & & $103.26(20)$ & 2.80 & 539.27 \\
\hline CFA $1\left(n_{\mathrm{CFA} 1}=435\right)$ & 16 & 845.10 & 27.86 & 1.60 & & $249.70(20)$ & 5.86 & 813.87 \\
\hline CFA $2\left(n_{\mathrm{CFA} 2}=434\right)$ & 13 & 725.14 & 23.18 & 1.77 & & $222.92(20)$ & 5.33 & 819.24 \\
\hline
\end{tabular}

Note. $\mathrm{KS}=$ Kolmogorov-Smirnov (Lilliefors), SW = Shapiro-Wilk, SF = Shapiro-Francia, AD = Anderson-Darling, M-Skew = Mardia's Skew, M-Kurtosis = Mardia's Kurtosis. ${ }^{a}$ Mahalanobis was 29.59 for the total sample and for all subsamples. ${ }^{*} p<.001$. 
Table A3. The fit of the single-factor model emerging from CFA1 was compared in the CFA1 subsample with outliers (MODEL 1, $\left.n_{\mathrm{CFAl}}=435\right)$ vs a subsample without outliers (MODEL 2, $\left.n_{\mathrm{CFAl}}=416\right)$ to evaluate the impact of outliers.

\begin{tabular}{ccccccccc}
\hline MODEL & $n$ & $\chi^{2}$ & $d f$ & CFI & RMSEA & $\begin{array}{c}\text { Model } \\
\text { Comparison }\end{array}$ & $\Delta$ CFI & $\Delta$ RMSEA \\
\hline $\begin{array}{c}\text { MODEL 1 } \\
\text { (WITH OUTLIERS) }\end{array}$ & 435 & 82.42 & 35 & .944 & .056 & - & \\
$\begin{array}{c}\text { MODEL 2 } \\
\text { (NO OUTLIERS) }\end{array}$ & 419 & 84.89 & 35 & .940 & .058 & $\begin{array}{c}\text { MODEL 2 vs } \\
\text { MODEL 1 }\end{array}$ & -.004 & .002 \\
\hline
\end{tabular}

Note. Estimator $=$ MLR, $d f=$ Degrees of freedom; CFI $=$ Comparative Fit Index; RMSEA $=$ Root Mean Square Error of Approximation

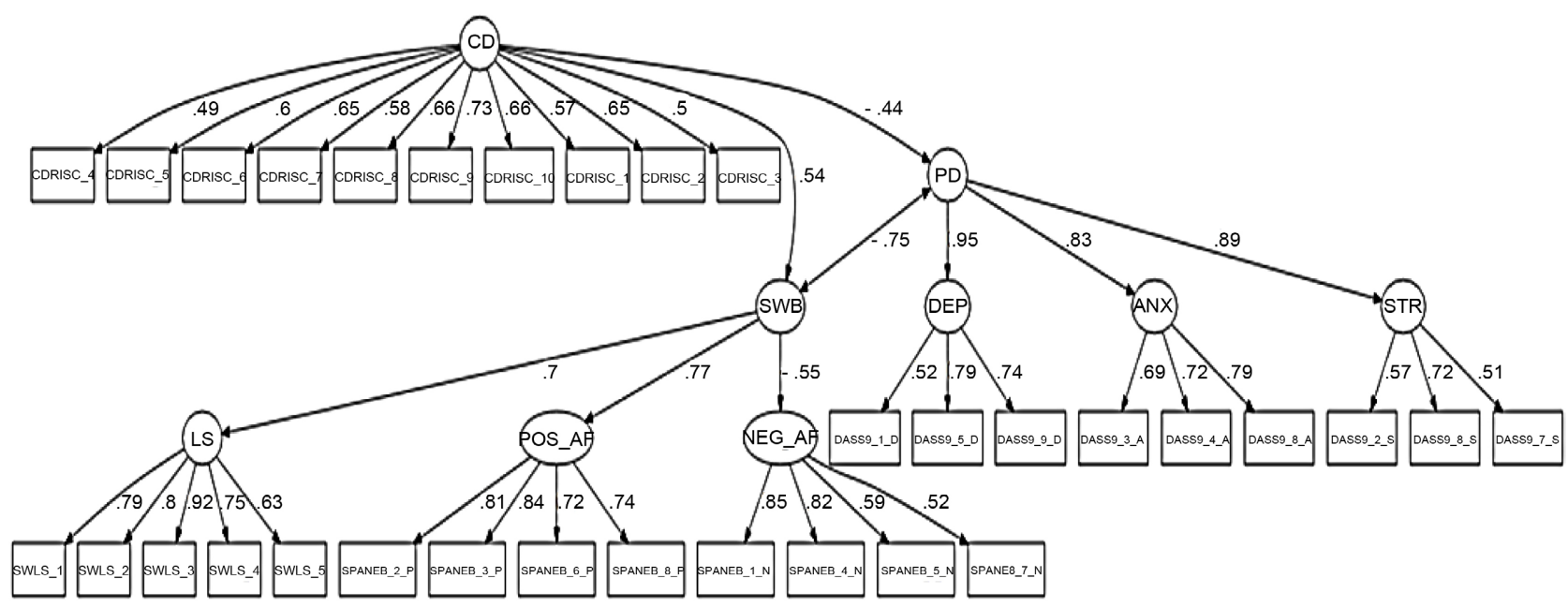

Figure A1. The full SEM model to test the predictive power of resilience operationalized with CD-RISC10 (CD) two second order latent variables of (1) subjective wellbeing (SWB; Diener et al., 1999) and (2) Psychological Distress (PD) with standardized coefficients $(p<.001)$. Note: CD = CD-RISC10 (Campbell-Sills \& Stein, 2007); LS = Satisfaction with Life Scale (SWLS, Diener et al., 1985); POS_AF = SPANE 8 Positive affect (Diener et al., 2010; Kyriazos et al. 2018a); NEG_AF= SPANE 8 Positive affect; DEP, ANX, STR = depression, anxiety and stress (DASS-9, Lovibond \& Lovibond, 1995; Kyriazos, et al., 2018b). 